\title{
Genome-wide association study reveals new loci for yield-related traits in Sichuan wheat germplasm under stripe rust stress
}

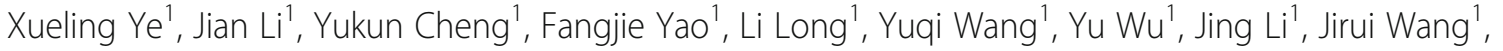 \\ Qiantao Jiang ${ }^{1}$, Houyang Kang ${ }^{1}$, Wei Li ${ }^{2}$, Pengfei Qi ${ }^{1}$, Xiujin Lan ${ }^{1}$, Jian Ma', Yaxi Liu' ${ }^{1}$ Y Yunfeng Jiang ${ }^{1}$, Yuming Wei ${ }^{1}$, \\ Xianming Chen $^{3}$, Chunji Liu ${ }^{4}$, Youliang Zheng ${ }^{1 *}$ and Guoyue Chen ${ }^{1 *}$ (D)
}

\begin{abstract}
Background: As one of the most important food crops in the world, increasing wheat (Triticum aestivum L.) yield is an urgent task for global food security under the continuous threat of stripe rust (caused by Puccinia striiformis f. sp. tritici) in many regions of the world. Molecular marker-assisted breeding is one of the most efficient ways to increase yield. Here, we identified loci associated to multi-environmental yield-related traits under stripe rust stress in 244 wheat accessions from Sichuan Province through genome-wide association study (GWAS) using 44,059 polymorphic markers from the $55 \mathrm{~K}$ single nucleotide polymorphism (SNP) chip.

Results: A total of 13 stable quantitative trait loci (QTLS) were found to be highly associating to yield-related traits, including 6 for spike length (SL), 3 for thousand-kernel weight (TKW), 2 for kernel weight per spike (KWPS), and 2 for both TKW and KWPS, in at least two test environments under stripe rust stress conditions. Of them, ten QTLs were overlapped or very close to the reported QTLs, three QTLs, QSL.sicau-1AL, QTKW.sicau$4 A L$, and QKWPS.sicau-4AL.1, were potentially novel through the physical location comparison with previous QTLs. Further, 21 candidate genes within three potentially novel QTLs were identified, they were mainly involved in the regulation of phytohormone, cell division and proliferation, meristem development, plant or organ development, and carbohydrate transport.

Conclusions: QTLs and candidate genes detected in our study for yield-related traits under stripe rust stress will facilitate elucidating genetic basis of yield-related trait and could be used in marker-assisted selection in wheat yield breeding.
\end{abstract}

Keywords: Wheat, 55 K SNP, Genome-wide association study, Yield-related traits, Stripe rust

\section{Background}

Wheat (Triticum aestivum L.) is one of the most important food crops in the world and provides $20 \%$ of calories consumed by humans [1]. Producing enough wheat for the growing population is one of the vital tasks for food security. However, abiotic and biotic stresses are among the greatest challenges to wheat production. As one of the most destructive wheat diseases in the world, stripe rust that is caused by fungus Puccinia striiformis Westend. $\mathrm{f}$.

\footnotetext{
* Correspondence: ylzheng@sicau.edu.cn; gychen@sicau.edu.cn

${ }^{1}$ Triticeae Research Institute, Sichuan Agricultural University, Wenjiang,

Chengdu, Sichuan 611130, People's Republic of China

Full list of author information is available at the end of the article
}

sp. tritici Erikss. (Pst) is a serious threat to wheat production [2]. Therefore, improving wheat yield under stripe rust stress is extremely urgent. Thus, identifying loci associated with yield-related traits under stripe rust stress may provide favourable alleles and their useful markers for breeding wheat cultivars with high yield in combination with stripe rust resistance.

The productive spike number per unit area, kernel number per spike (KPS) and thousand-kernel weight (TKW) are key components of wheat yield. The productive spike number per unit area mainly depends on the fertile tiller number (FTN). Most spike-related traits, such as spike length (SL), spikelet number per spike

(C) The Author(s). 2019 Open Access This article is distributed under the terms of the Creative Commons Attribution 4.0 International License (http://creativecommons.org/licenses/by/4.0/), which permits unrestricted use, distribution, and 
(SIPS), kernel number per spikelet (KPSl) and the spikelet compactness (SlC), affect the KPS and thus also affect the yield [3-5]. Many studies have showed that the SL has a positive correlation with KPS and SIPS $[3,4,6,7]$. Moreover, Mohsin et al. [8] reported that the SL and the KPS had a positive effect on grain yield. Würschum et al. [7] demonstrated that KPSl was positively correlated with the KPS. The SlC is positively correlated with SIPS, but negatively related to SL $[3,6,9]$. The TKW, which depends on the kernel weight, is associated with the accumulation of starch produced by photosynthesis [10, 11]. Therefore, wheat yield is a complex quantitative trait contributed by many morphological, physiological and biochemical components, all of which can be improved to increase the yield directly or indirectly.

Genome-wide association study (GWAS) is a powerful tool to identify loci associated to target traits based on linkage disequilibrium (LD) using natural populations. It is a rapid and cost-effectiveness way to detect target markers for marker-assisted breeding. GWAS was first used in human research and has made great contributions to identify genes associated to human diseases [12-16]. The GWAS approach has been widely used in plant and animal research [17-21]. For wheat, GWAS has been successfully used for identifying quantitative trait loci (QTLs) for disease resistance and yield [22-25]. The release of the high-quality genome reference IWGSC RefSeq v1.0 [26] has provided great assistance to detect linked markers and candidate genes for target traits. The availability of marker arrays for high throughput genotyping is a key for GWAS. There are many SNP arrays have been developed for wheat, such as $9 \mathrm{~K}, 35 \mathrm{~K}, 55 \mathrm{~K}, 90 \mathrm{~K}$, $660 \mathrm{~K}$ and $820 \mathrm{~K}$. These arrays are able to provide highdensity maps for detecting loci associated with target traits.

In the present study, 244 wheat accessions (including 79 landraces and 165 cultivars) from Sichuan Province, China were genotyped by using the wheat $55 \mathrm{~K}$ SNP Array [27]. Based on multi-environmental yield-related traits data under stripe rust stress, a GWAS was conducted to identify the associated loci for yield-related traits, such as FTN, SL, SIPS, Kernel weight per spike (KWPS), TKW and SlC. The research further analysed the genetic architecture of the yield-related traits, provide molecular markers to use in genome selection for wheat high-yield breeding and may provide new insights for genetic dissection of other complex quantitative traits in wheat.

\section{Results}

Phenotypic characterization of eight yield-related traits The yield-related traits were collected from Chongzhou in 2017, 2018 (CZ17, CZ18), Mianyang in 2017 (MY17) under stripe rust stress, and Chongzhou in 2017, 2018 without Pst inoculation as control (CZ17ck, CZ18ck). The materials in CZ17ck and CZ18ck were set as control without inoculating with Pst. The materials in CZ17, MY17 and CZ18 were inoculated with mixed Pst isolates. The Pearson correlation coefficient analysis showed the significant correlations among the five environments when the seven yield-related traits except FTN were analysed separately. FTN had significant correlation among the four test environments except for CZ18 (Additional file 1). Shown as Fig. 1, the genotypeby-year interaction was significant for all measured yield-related traits except KWPS, while the genotype-bylocation interaction was not significant. The FTN, SL, KPSl and KPS in 2017 all performed better than in 2018, while the SIPS, TKW and SlC all performed better in 2018 than in 2017. Moreover, the plants in CZ17 and MY17 showed lower KPS, KWPS and TKW than in CZ17ck, and the plants in CZ18 showed lower KWPS, TKW and SlC than in CZ18ck.

The phenotypic variations of eight yield-related traits under stripe rust stress were determined based on their best linear unbiased prediction (BLUP) values (Table 1). FTN and KPSl ranged from 6 to 9 and from 3.7 to 4.3, respectively. SL ranged from 9.3 to $14.1 \mathrm{~cm}$. The ranges of SIPS and KPS were 18 to 25 and 41 to 62, respectively. The lowest KWPS was $1.21 \mathrm{~g}$ (g) and TKW 24.26 $\mathrm{g}$, while the highest KWPS was $2.99 \mathrm{~g}$ and TKW $52.02 \mathrm{~g}$. The maximal SlC was 2.53 , and the minimum value was 1.54. In addition, SIPS, TKW and SlC had high heritabilities (0.78, 0.80 and 0.86, respectively) whereas FTN and KPSl had relatively low heritabilities $(0.37$ and 0.31 , respectively). The Shannon-Weaver diversity index analysis showed that KPS $\left(H^{\prime}=0.86\right)$ and TKW $\left(H^{\prime}=\right.$ $0.85)$ exhibited relatively high diversity compared to FTN $\left(H^{\prime}=0.68\right)$ and SIPS $\left(H^{\prime}=0.67\right)$.

\section{Phenotypic differences between landraces and cultivars under stripe rust stress}

The 244 entries consisted of 79 landraces and 165 cultivars. The $t$-test identified significant differences between landraces and cultivars in FTN, SIPS, KPSl, KWPS, TKW and SlC under stripe rust stress based on the BLUP values (Table 2). The mean BLUP value of the landrace group was significantly higher than that of the cultivar group for FTN (7.3), SIPS (21) and SIC (1.95), whereas the cultivar group exhibited significant higher KPSl (4.1), KWPS (2.19) and TKW (42.14) values than the landrace group (Table 2). In addition, analysis of the Shannon-Weaver diversity indices showed that the landrace group exhibited higher phenotypic diversity in FTN, SL, SIPS and SIC than the cultivar group, whereas the latter group had higher diversity in KPSl, KWPS and TKW (Table 2). 


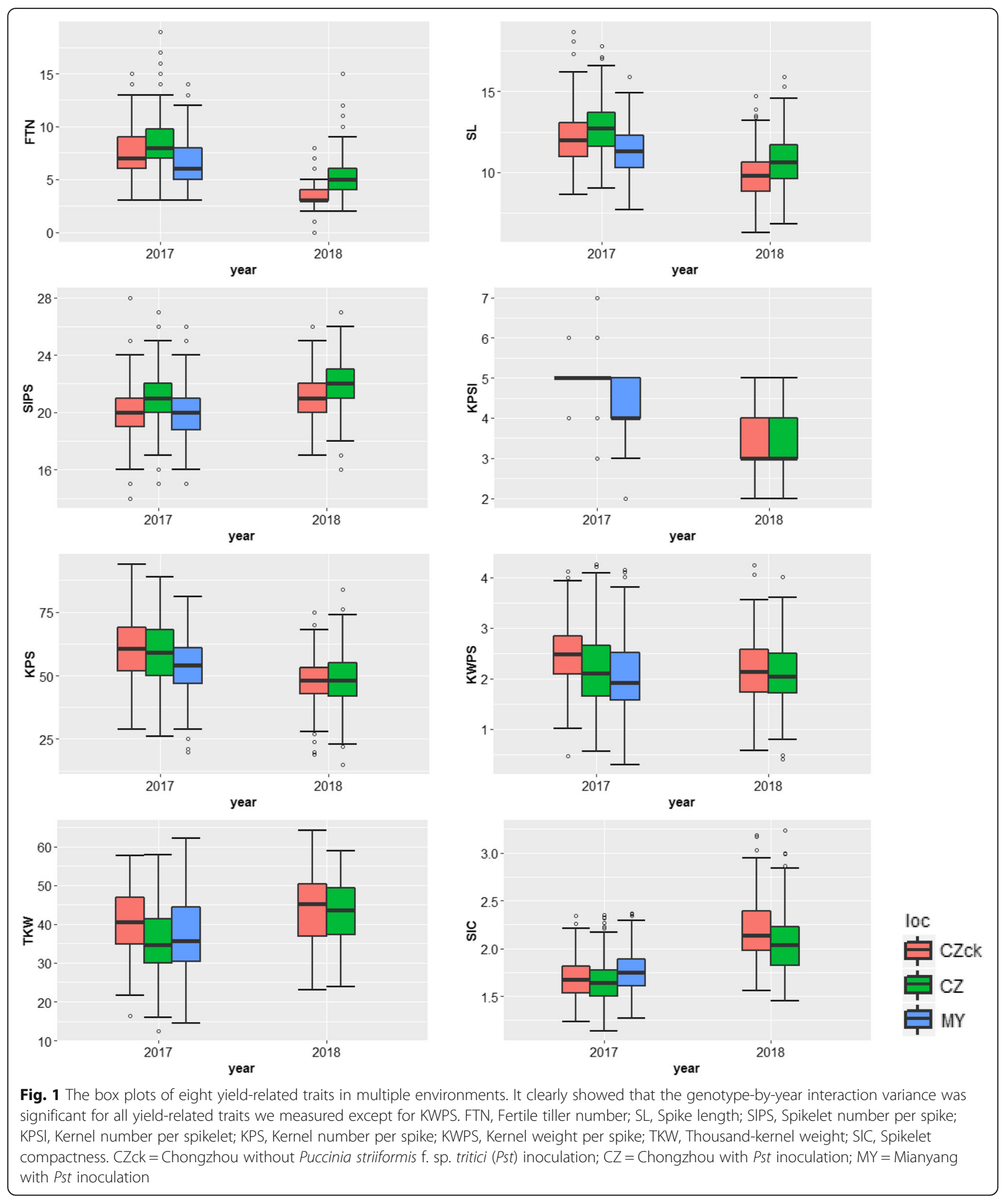

Correlations among yield-related traits under stripe rust stress and stripe rust reaction

Pearson correlation coefficient analysis among the yield components and stripe rust reaction measured as IT
(Additional file 2) showed that IT was significantly negatively correlated with FTN, KPS, KWPS and TKW; SlC was significantly negatively correlated with SL and TKW; FTN negatively correlated with KPSl, KWPS and 
Table 1 The phenotypic variations for 244 wheat accessions under stripe rust stress based on BLUP values

\begin{tabular}{lllllllll}
\hline Trials & FTN & SL $(\mathrm{cm})$ & SIPS & KPSI & KPS & KWPS (g) & TKW (g) & SIC \\
\hline Min & 6 & 9.3 & 18 & 3.7 & 41 & 1.21 & 24.26 & 1.54 \\
Max & 9 & 14.1 & 25 & 4.3 & 62 & 2.99 & 52.02 & 2.53 \\
Mean & 6.8 & 11.6 & 21 & 4.0 & 53 & 2.09 & 39.54 & 1.88 \\
STDEV & 0.64 & 0.85 & 1.16 & 0.11 & 3.94 & 0.30 & 5.68 & 0.17 \\
CV & 0.09 & 0.07 & 0.06 & 0.03 & 0.07 & 0.14 & 0.14 & 0.09 \\
$H^{2}$ & 0.37 & 0.69 & 0.78 & 0.31 & 0.51 & 0.59 & 0.80 & 0.86 \\
$H^{\prime}$ & 0.68 & 0.79 & 0.67 & 0.79 & 0.86 & 0.80 & 0.85 & 0.78 \\
\hline
\end{tabular}

BLUP The best linear unbiased prediction

FTN Fertile tiller number, SL Spike length, SIPS Spikelet number per spike, KPSI Kernel number per spikelet, KPS Kernel number per spike, KWPS Kernel weight per spike, TKW Thousand-kernel weight, SIC Spikelet compactness, $\mathrm{cm}$ centimetre, $g$ gram

STDEV Standard deviation, CV Coefficient of variation, $H^{2}$, The broad sense heritability; $H^{\prime}$, The Shannon-Weaver diversity index

TKW; and SlPS negative correlated with TKW (Fig. 2). Positive correlation was detected between SlC with FTN and SIPS; between FTN and SIPS; between SIPS with KPS and SL; and among KPS, SL, KPSl, KWPS and TKW except between TKW and KPS (Fig. 2). In addition, the correlation network analysis showed a very strong correlation between KWPS and TKW (0.79), and between KPS and KWPS (0.62) (Fig. 2).

\section{The impact of stripe rust on yield-related traits}

The Pearson correlation coefficient analysis showed IT was negatively correlated with FTN, KPS, KWPS and TKW. In order to further understand the stripe rust effects on yield traits, we compared the control plots (CZ17ck and CZ18ck) and the inoculated plots (MY17, CZ17, and CZ18) (Table 3). The control plots had higher KPS, KWPS and TKW than inoculated plots, whereas the inoculated plots had higher FTN than the control plots (Table 3). Based on the IT data in the inoculated fields, of the 244 accessions, 169 were resistant and 75 susceptible (Additional file 2). The resistant accessions exhibited higher FTN, KPS, KWPS, and TKW than the susceptible accessions in both inoculated and non-inoculated plots (Table 3). However, compared with the noninoculated plots, FTN increased by 15.5 and $15.4 \%$ for the resistant and susceptible accessions inoculated with Pst, respectively. In addition, with Pst inoculation, KPS, KWPS and TKW of resistance accessions were reduced by $1.5,8.5$ and $5.6 \%$, and KPS, KWPS and TKW of susceptible ones reduced by $2.7,11.8$ and 10.2\%, respectively (Table 3 ).

\section{Genome-wide association analyses}

Based on the genotyping data generated using the 55 K SNP array (Affymetrix Axiom Wheat55K), a total of 44,059 high-quality SNP markers were selected for genetic variation (Additional file 3) [27]. The previous result of the analysis of population structure (Qmatrix) showed the optimal $\Delta \mathrm{K}$ value was 2 , indicating that the 244 accessions could be divided into 2 sub-populations. Sub-population 1 harboured 78 accessions, including 77 landraces and one cultivar. Sub-population 2 contained 166 accessions, including 164 cultivars and 2 landraces [27]. Significant differences were observed in the BLUP values of five yieldrelated traits (FTN, SIPS, KWPS, TKW and SlC) between two sub-populations. The sub-population 1 mainly contained landraces exhibited higher FTN, SIPS and SIC than those in sub-population 2, while the accessions in sub-population 2 showed higher KWPS and TKW than those in sub-population 1 (Fig. 3, Additional file 4). The LD half decay distance was $2.12 \mathrm{Mb}$ based on the $r^{2}$ values between significant pairs of intra-chromosomal SNP markers with physical distances [27]. Significant associated loci within a genomic region of $2.12 \mathrm{Mb}$ or less on the same chromosome were treated as a same QTL.

Subsequently, GWAS was conducted to identify loci associated with yield-related traits in three environments under stripe rust stress based on the MLM model with $\mathrm{Q}+\mathrm{K}$ as covariates. We identified 7, 9 and 6 high confidence markers $\left(-\log _{10} P>3\right)$ associated with SL, TKW and KWPS, respectively. Of them, four markers associated with both TKW and KWPS (Table 4). All of these high confidence markers were detected in at least two of the environments. Moreover, 16 favourable SNP alleles were detected (Table 4, Additional file 5). Accessions possessing the favourable alleles performed better in SL, KWPS and TKW than those did not have the favourable alleles (Fig. 4). Shown as Fig. 5, the loci with high confidences of association in the three environments were displayed as Manhattan plots with $P$ values across the 21 wheat chromosomes. Based on the LD distance of 2.12 $\mathrm{Mb}$, the associated loci were determined as 13 QTLs (Table 4). The six QTLs associated with SL were mapped on chromosome 1AL, 2AL, 2DS, 4AS and 5AL, three QTLs associated with TKW were located on chromosome 1BL, 2AS, and 4AL, two QTLs associated with KWPS were all mapped on chromosome 4AL, two QTLs associated with both KWPS and TKW were mapped on chromosome 1BL and 2AS. The two QTLs associated with KWPS located on chromosome 4AL explained up to $20 \%$ phenotypic variation, and the QTL on $1 \mathrm{AL}$ associated with SL also explained high phenotypic variation, ranging from 8.3 to $10.6 \%$ and was detected in all three environments. Moreover, comparing with the physical locations of reported QTLs or genes associated with SL, KWPS and TKW based on the reference RefSeq v1.0 [26], three of the QTLs were potentially novel (Table 4). 
Ye et al. BMC Genomics (2019) 20:640

Page 5 of 17

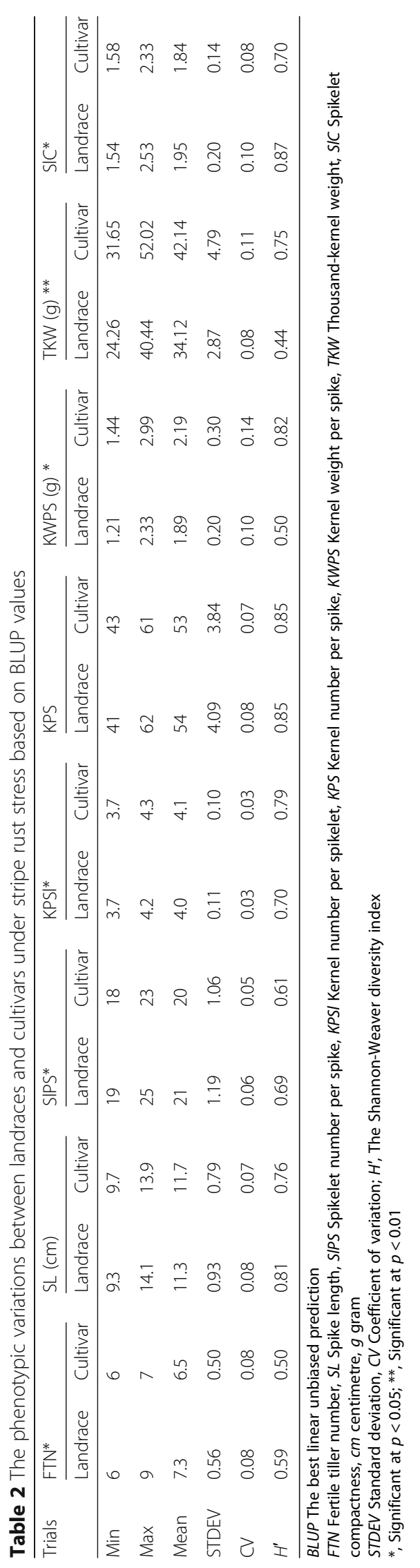



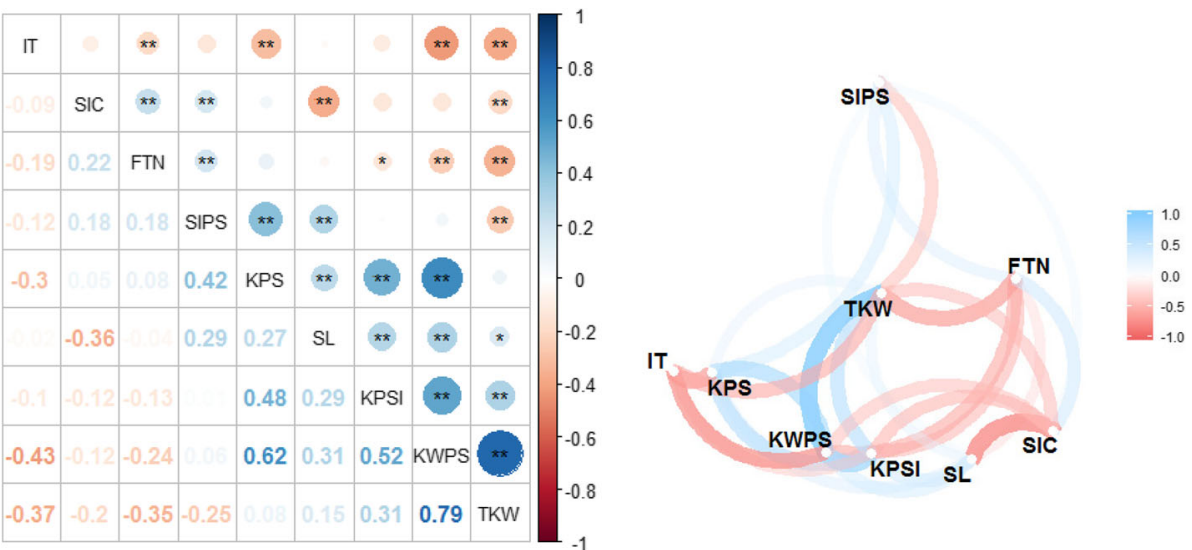

Fig. 2 The correlations matrix and network analysis among eight yield-related traits and infection type (IT). FTN, Fertile tiller number; SL, Spike length; SIPS, Spikelet number per spike; KPSI, Kernel number per spikelet; KPS, Kernel number per spike; KWPS, Kernel weight per spike; TKW, Thousand-kernel weight; SIC, Spikelet compactness. *, Significant at $p<0.05$; **, Significant at $p<0.01$

\section{Putative candidate genes of the three potentially novel} QTLS

Based on the Chinese Spring reference RefSeq v1.0 (IWGSC) and RefSeq Annotation v1.1 [26], 59, 29 and 33 genes included in QSL.sicau-1AL, QTKW.sicau- $4 A L$ and QKWPS.sicau-4AL.1 region were selected. Of them, 21 candidate genes were predicted to be involved in the regulation of phytohormone, cell division and proliferation, meristem development, plant or organ development, and carbohydrate transport (Additional file 6).

\section{Discussion}

Characterization of yield-related traits under stripe rust stress

We evaluated 244 wheat accessions in three field environments under stripe rust stress (CZ17, MY17 and CZ18) and two sites without inoculating Pst (CZ17ck

Table 3 The difference in yield-related traits between resistant and susceptible accessions with or without Pst inoculation

\begin{tabular}{|c|c|c|c|c|c|c|}
\hline \multirow[t]{2}{*}{ Traits } & \multirow[t]{2}{*}{ Type } & \multicolumn{2}{|l|}{ Range } & \multicolumn{2}{|c|}{ Mean values } & \multirow[t]{2}{*}{ Difference $^{c}$} \\
\hline & & Control $^{a}$ & Inoculation $^{\mathrm{b}}$ & Control $^{a}$ & Inoculation $^{\mathrm{b}}$ & \\
\hline \multirow[t]{2}{*}{$\mathrm{FTN}^{* *}$} & $\mathrm{R}$ & $3-11$ & $6-9$ & 5.94 & 6.86 & $+15.5 \%$ \\
\hline & $S$ & $4-10$ & $6-8$ & 5.65 & 6.52 & $+15.4 \%$ \\
\hline \multirow[t]{2}{*}{$\mathrm{SL}(\mathrm{cm})$} & $\mathrm{R}$ & $7.7-15.7$ & $9.3-13.9$ & 10.96 & 11.57 & - \\
\hline & $\mathrm{S}$ & $8.0-16.0$ & $9.8-14.1$ & 10.78 & 11.51 & - \\
\hline \multirow[t]{2}{*}{ SIPS } & $\mathrm{R}$ & $17-25$ & $18-23$ & 20.85 & 20.80 & - \\
\hline & $\mathrm{S}$ & $18-24$ & $18-25$ & 20.49 & 20.39 & - \\
\hline \multirow[t]{2}{*}{ KPSI } & $\mathrm{R}$ & $3.0-5.5$ & $3.7-4.3$ & 4.18 & 4.05 & - \\
\hline & $S$ & $3.0-5.0$ & $3.7-4.3$ & 4.10 & 4.03 & - \\
\hline \multirow[t]{2}{*}{$\mathrm{KPS}^{* *}$} & $\mathrm{R}$ & $28-75$ & $43-62$ & 54.53 & 53.72 & $-1.5 \%$ \\
\hline & $\mathrm{S}$ & $30-72$ & $41-60$ & 52.49 & 51.09 & $-2.7 \%$ \\
\hline \multirow[t]{2}{*}{$\operatorname{KWPS}(g)^{* *}$} & $\mathrm{R}$ & $0.84-3.61$ & $1.32-2.99$ & 2.36 & 2.16 & $-8.5 \%$ \\
\hline & $\mathrm{S}$ & $0.68-3.36$ & $1.21-2.52$ & 2.20 & 1.94 & $-11.8 \%$ \\
\hline \multirow[t]{2}{*}{ TKW $(g)^{* *}$} & $\mathrm{R}$ & $24.91-61.23$ & $28.27-52.02$ & 42.95 & 40.54 & $-5.6 \%$ \\
\hline & $\mathrm{S}$ & $23.38-54.88$ & $24.26-45.26$ & 41.54 & 37.31 & $-10.2 \%$ \\
\hline \multirow[t]{2}{*}{$\mathrm{SIC}$} & $\mathrm{R}$ & $1.44-2.76$ & $1.54-2.53$ & 1.91 & 1.89 & - \\
\hline & $S$ & $1.50-2.44$ & $1.58-2.33$ & 1.90 & 1.86 & - \\
\hline
\end{tabular}

FTN Fertile tiller number, SL Spike length, SIPS Spikelet number per spike, KPSI Kernel number per spikelet, KPS Kernel number per spike, KWPS Kernel weight per spike, TKW Thousand-kernel weight, SIC Spikelet compactness, $\mathrm{cm}$ centimetre, $g$ gram

$R$ Resistant materials, $S$ Susceptible materials

${ }^{a}$, the locations without Pst inoculation; ${ }^{\text {, }}$, the locations with Pst inoculation. ${ }^{c}$, comparing with control, the increase $(+)$ or decrease $(-)$ percentage of yield-related traits under stripe rust stress

**, the significant difference in the traits between control and inoculation at $p<0.01$ 


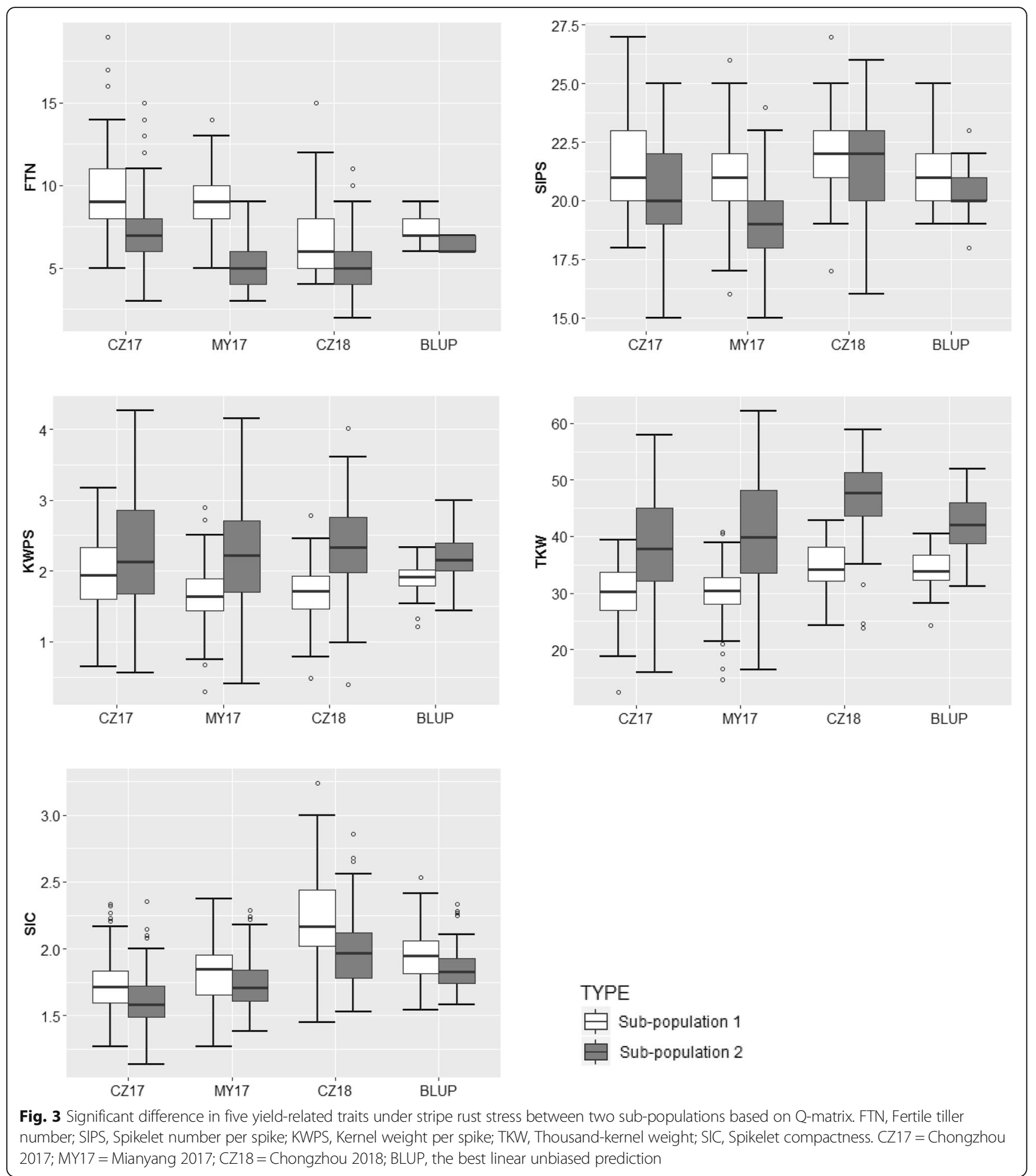

and CZ18ck) in Sichuan. The seven yield-related traits displayed significant differences between 2017 and 2018 except KWPS. FTN, SL, KPSl and KPS in 2017 performed better than in 2018, while SIPS, TKW and SlC in 2018 were better than in 2017. Different traits are formed in different growth periods and required and also affected by different growth conditions, such as water, temperature, soil fertility, light and others. Compared the weather conditions during the wheat growing seasons between 2017 and 2018, we considered temperature was the main factor for the difference in FTN between the 2 years (Additional file 7). From the 
Table 4 The details of QTLS associated with yield-related traits under stripe rust stress

\begin{tabular}{|c|c|c|c|c|c|c|c|c|c|}
\hline QTL name & SNP Marker & $\mathrm{Chr}^{\mathrm{a}}$ & Position & Alleles $^{\mathrm{b}}$ & Traits & $\begin{array}{l}P \text { values } \\
(-\log ) \text { e }\end{array}$ & $\begin{array}{l}\text { Marker } \mathrm{R}^{2} \\
(\%)\end{array}$ & Environments & Reference \\
\hline QSL.sicau-1AL & $\begin{array}{l}A X- \\
110408975\end{array}$ & $1 \mathrm{~A}$ & $\begin{array}{l}\text { 590,994, } \\
911\end{array}$ & $\underline{T} / \mathrm{C}$ & $S L$ & $3.9-4.3$ & $8.3-10.5$ & $\begin{array}{l}\text { CZ17, CZ18, } \\
\text { MY17 }\end{array}$ & d \\
\hline \multirow{4}{*}{$\begin{array}{l}\text { QTKW. } \\
\text { sicau-1BL.1 \& } \\
\text { QKWPS.sicau-1BL }\end{array}$} & $\begin{array}{l}A X- \\
109335890\end{array}$ & $1 \mathrm{~B}$ & $\begin{array}{l}670,593 \\
327\end{array}$ & $\mathrm{~A} / \mathrm{C}$ & $\begin{array}{l}\text { KWPS \& } \\
\text { TKW }\end{array}$ & $\begin{array}{l}4.0-4.3 \& \& \\
3.7-4.5\end{array}$ & $\begin{array}{l}6.7-7.7 \& \& \\
6.5-8.6\end{array}$ & CZ17, MY17 & \multirow[t]{4}{*}{ Börner et al. 2002} \\
\hline & $\begin{array}{l}\text { AX- } \\
109849833\end{array}$ & 1B & $\begin{array}{l}670,678 \\
079\end{array}$ & $\mathrm{G} / \underline{\mathrm{T}}$ & $\begin{array}{l}\text { KWPS \& } \\
\text { TKW }\end{array}$ & $\begin{array}{l}4.2-6.3 \& \& \\
3.6-4.7\end{array}$ & $\begin{array}{l}8.9-13.6 \& \\
7.8-10.6\end{array}$ & CZ17, MY17 & \\
\hline & $\begin{array}{l}A X- \\
111525685\end{array}$ & 1B & $\begin{array}{l}670,781 \\
552\end{array}$ & $C / \underline{G}$ & $\begin{array}{l}\text { KWPS \& } \\
\text { TKW }\end{array}$ & $\begin{array}{l}3.3-4.5 \& \\
3.7-3.9\end{array}$ & $\begin{array}{l}6.8-9.3 \& \& \\
7.6-8.5\end{array}$ & CZ17, MY17 & \\
\hline & $\begin{array}{l}A X- \\
109299717\end{array}$ & $1 \mathrm{~B}$ & $\begin{array}{l}670,794 \\
681\end{array}$ & $\mathrm{G} / \underline{A}$ & TKW & $3.6-4.5$ & $7.6-9.7$ & CZ17, MY17 & \\
\hline $\begin{array}{l}\text { QTKW. } \\
\text { sicau-1BL.2 }\end{array}$ & $\begin{array}{l}A X- \\
111471952\end{array}$ & $1 \mathrm{~B}$ & $\begin{array}{l}681,682 \\
184\end{array}$ & $\mathrm{~A} / \underline{G}$ & TKW & $3.3-3.5$ & $7.1-7.5$ & CZ17, MY17 & Nezhad et al. 2012 \\
\hline \multirow[t]{2}{*}{$\begin{array}{l}\text { QTKW. } \\
\text { sicau-2AS.1 }\end{array}$} & $\begin{array}{l}A X- \\
108781797\end{array}$ & $2 \mathrm{~A}$ & $2,795,252$ & $\underline{G} / \mathrm{C}$ & TKW & $3.2-4.5$ & $6.5-9.5$ & CZ17, MY17 & \multirow[t]{2}{*}{$\begin{array}{l}\text { Cui et al. 2014; Zhang et al. } \\
2014\end{array}$} \\
\hline & $\begin{array}{l}A X- \\
111079592\end{array}$ & $2 \mathrm{~A}$ & $3,541,651$ & $\underline{G} / \mathrm{A}$ & TKW & $3.1-3.4$ & $6.4-7.0$ & CZ17, MY17 & \\
\hline $\begin{array}{l}\text { QTKW. } \\
\text { sicau-2AS.2 \& } \\
\text { QKWPS.sicau-2AS }\end{array}$ & $\begin{array}{l}A X- \\
108919444\end{array}$ & $2 \mathrm{~A}$ & $\begin{array}{l}24,057 \\
418\end{array}$ & $\mathrm{~T} / \mathrm{G}$ & $\begin{array}{l}\text { KWPS \& } \\
\text { TKW }\end{array}$ & $\begin{array}{l}3.3-5.1 \& \\
3.2-3.4\end{array}$ & $\begin{array}{l}5.5-9.2 \& \& \\
5.4-6.2\end{array}$ & CZ17, MY17 & Zhang et al. 2014 \\
\hline QSL.sicau-2AL & $\begin{array}{l}A X- \\
110079477\end{array}$ & $2 \mathrm{~A}$ & $\begin{array}{l}432,588 \\
841\end{array}$ & $\underline{T} / \mathrm{A}$ & $S L$ & 3.2 & $6.5-6.6$ & $\mathrm{CZ17}, \mathrm{MY} 17$ & Deng et al. 2017 \\
\hline QSL.sicau-2DS & $\begin{array}{l}A X- \\
110647062\end{array}$ & $2 \mathrm{D}$ & $\begin{array}{l}23,025 \\
488\end{array}$ & $\underline{\mathrm{A}} / \mathrm{T}$ & $S L$ & $3.5-3.7$ & $7.1-7.6$ & CZ17, MY17 & Chai et al. 2018 \\
\hline QSL.sicau-4AS & $\begin{array}{l}A X- \\
109296730\end{array}$ & $4 \mathrm{~A}$ & $\begin{array}{l}68,155 \\
791\end{array}$ & $\underline{C} / \mathrm{A}$ & $S L$ & $3.5-3.7$ & $7.2-7.5$ & CZ17, MY17 & Luo et al. 2016 \\
\hline QTKW.sicau-4AL & $\begin{array}{l}\text { AX- } \\
109993853\end{array}$ & $4 \mathrm{~A}$ & $\begin{array}{l}538,150 \\
807\end{array}$ & $\mathrm{G} / \underline{T}$ & TWK & $3.2-3.7$ & $7.7-9.0$ & CZ17, MY17 & d \\
\hline $\begin{array}{l}\text { QKWPS. } \\
\text { sicau-4AL.1 }\end{array}$ & $\begin{array}{l}A X- \\
109830112\end{array}$ & $4 \mathrm{~A}$ & $\begin{array}{l}569,760 \\
052\end{array}$ & $\mathrm{G} / \underline{A}$ & KWPS & $3.4-8.7$ & $7.4-20.4$ & MY17, CZ18 & d \\
\hline $\begin{array}{l}\text { QKWPS. } \\
\text { sicau-4AL.2 }\end{array}$ & $\begin{array}{l}A X- \\
111088719\end{array}$ & $4 \mathrm{~A}$ & $\begin{array}{l}620,950 \\
639\end{array}$ & $\mathrm{~T} / \underline{\mathrm{C}}$ & KWPS & $3.1-8.5$ & $6.5-20.0$ & MY17, CZ18 & Cui et al. 2013 \\
\hline \multirow[t]{2}{*}{ QSL.sicau-5AL.1 } & $\begin{array}{l}A X- \\
109624254\end{array}$ & $5 \mathrm{~A}$ & $\begin{array}{l}595,708 \\
738\end{array}$ & $\underline{G} / \mathrm{A}$ & $S L$ & $3.3-4.5$ & $7.8-9.2$ & CZ17, CZ18 & \multirow[t]{2}{*}{ Gao et al. 2015} \\
\hline & $\begin{array}{l}A X- \\
110717909\end{array}$ & $5 A$ & $\begin{array}{l}595,950 \\
156\end{array}$ & $\underline{C} / \mathrm{A}$ & $S L$ & $3.1-3.4$ & $7.7-8.0$ & CZ17, CZ18 & \\
\hline QSL.sicau-5AL.2 & $\begin{array}{l}\text { AX- } \\
110521338\end{array}$ & $5 \mathrm{~A}$ & $\begin{array}{l}621,939 \\
257\end{array}$ & $\underline{T} / \mathrm{C}$ & $S L$ & $3-3.4$ & $7.4-7.6$ & MY17, CZ18 & Liu et al. 2014 \\
\hline
\end{tabular}

${ }^{\mathrm{a}}$,Chromosome; ${ }^{\mathrm{b}}$, The alleles marked with underline are favorable alleles

d, the potentially novel QTL

SL Spike length, KWPS Kernel weight per spike, TKW Thousand-kernel weight

CZ17 Chongzhou 2017, MY17 Mianyang 2017, CZ18 Chongzhou 2018

three-leaf stage to the beginning of stem-elongation in the vegetative growth period was the important time to produce tillers [28], and one of the key factors is temperature. Temperatures below $3{ }^{\circ} \mathrm{C}$ are not good for tiller development, and the optimal range is $13-18^{\circ} \mathrm{C}$ $[29,30]$. Wheat in Sichuan Province is sowed from late October to early November, and the vegetative growth is about from planting time to the following March. The weather conditions from December, 2016 to February, 2017 (CZ17 and MY17) were warm, but the temperatures in December, 2017 to February, 2018 (CZ18) were lower than in CZ17 and MY17. The lowest temperature in CZ18 was less than $0^{\circ} \mathrm{C}$ (Additional file 7), which seriously reduced the tiller number. Thus, we speculated that the warm weather was the main factor for the higher number of fertile tillers during the vegetative growth period from 2016 to 2017.

Yield-related traits SIPS, TKW and SIC exhibited relatively higher broad-sense heritabilities, while FTN and KPSl showed lower broad-sense heritabilities (Table 1). The results indicated that the environments had a great influence on FTN and KPSl, but less effect on SIPS, TKW and SlC. In other words, SIPS, TKW and SlC were more stable than FTN and KPSl. Consistent with many 


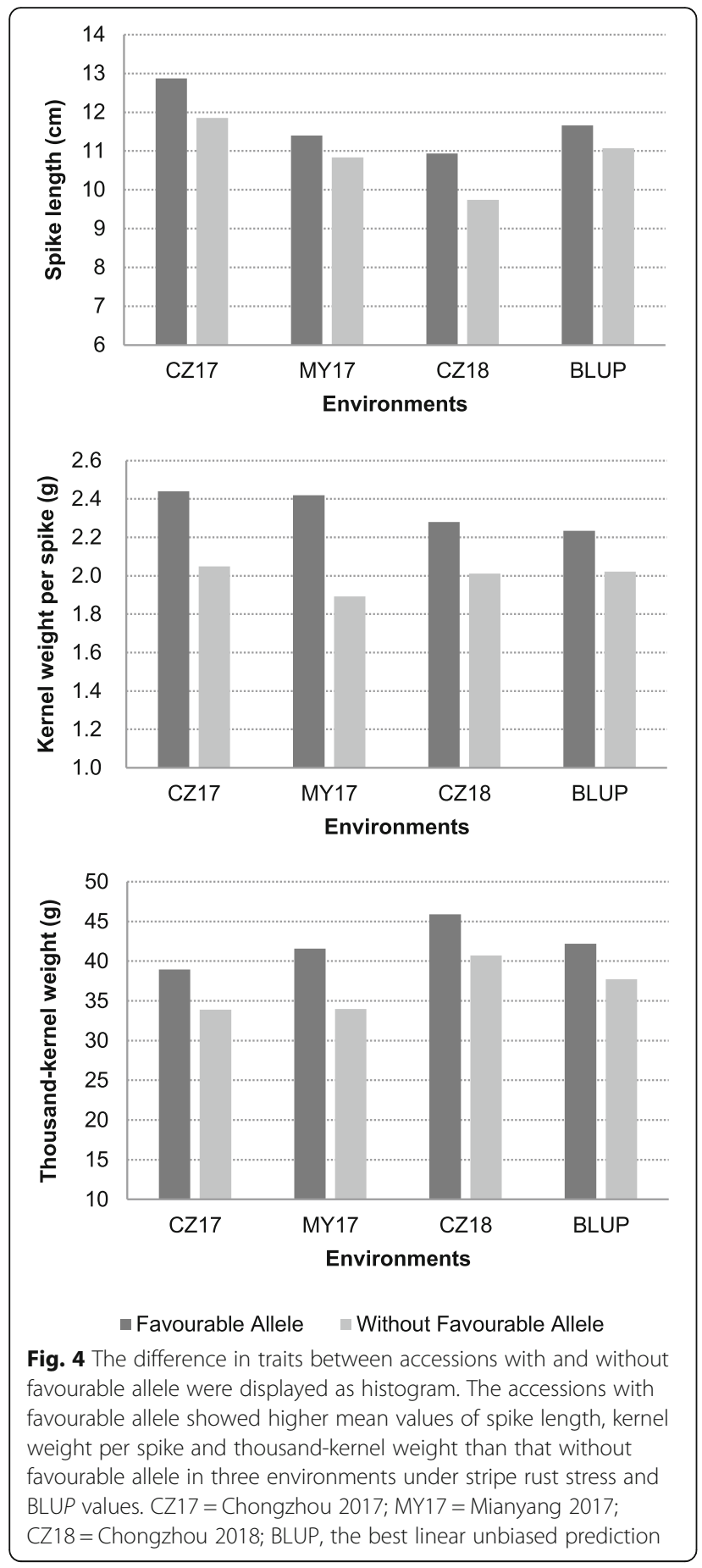

other reports, FTN had a low heritability and was strongly influenced by environments $[5,9,31]$ and KPSl also displayed relatively low heritability, whereas SIPS, TKW and SlC had relatively higher heritabilities [3, 9, 32-34].

The Shannon-Weaver diversity indices reflected the phenotypic diversity to some extent. KPS and TKW showed the highest phenotype diversities and FTN and SIPS displayed the lowest diversities in this study, which were consistent with the reports of $\mathrm{Li}$ et al. [35] and Liu et al. [36]. A high phenotypic diversity is beneficial to phenotypic improvement in breeding. As the important components of yield, KPS and TKW exhibited high phenotypic diversities, and accessions with favourable alleles for these traits can be used as elite germplasm for breeding whet cultivars high yield potential.

Compared with the non-inoculation control experiments (CZ17ck and CZ18ck), the accessions under stripe rust stress (CZ17, MY17 and CZ18) exhibited lower KPS, KWPS and TKW. The further comparison between the non-inoculation control and Pst-inoculation indicated that many accessions exhibited significantly lower KPS, KWPS and TKW, but higher FTN under stripe rust stress. However, stripe rust did not significantly affect SL, SIPS, KPSl and SIC. The resistant accessions exhibited higher mean values of yield-related traits than susceptible accessions no matter inoculated or not inoculated indicating that stripe rust resistance protects most of the yield-related traits.

Interestingly, both resistant and susceptible accessions under stripe rust stress exhibited higher FTN. As we discussed above, FTN is mainly determined during the vegetative growth period from the three-leaf stage to the beginning of stem-elongation stage [28]. This period is prior to the Pst inocultion. So, we speculated that the stripe rust should not have significant effects on FTN. There were many reports also demonstrated that the stripe rust didn't affect tiller number [37, 38]. The differences in FTN between the control and Pst-inoculation fields could be due to other conditions such as weather, water, and soil fertility rather than stripe rust.

There is no doubt that stripe rust can reduce yield, especially the KPS, KWPS and TKW [39-41]. In the present study, the values of KPS, KWPS and TKW of resistant accessions under stripe rust stress were reduced by $1.5,8.5$ and $5.6 \%$, while those of susceptible accessions under stripe rust stress were reduced 2.7, 11.8 and $10.2 \%$ separately. Thus, susceptible accessions had more serious reduction by stripe rust than resistant accessions. In other words, resistance can effectively reduce the losses of KPS, KWPS and TKW under stripe rust stress. We inoculated wheat plants with Pst around the shooting stage in January and rust appeared on flag leaves at the heading stage, and reached the highest severity around the anthesis to grain filling stage. The anthesis stage is the important time to product kernels (e.g. KPS) [42] and the grain filling period is the key time to determine the kernel weight (e.g. KWPS and TKW) [43]. The Pst pathogen produced abundant urediniospore during the flag-leaf stage, and thus reduced the photosynthetic area, which caused the decrease of sugar production 


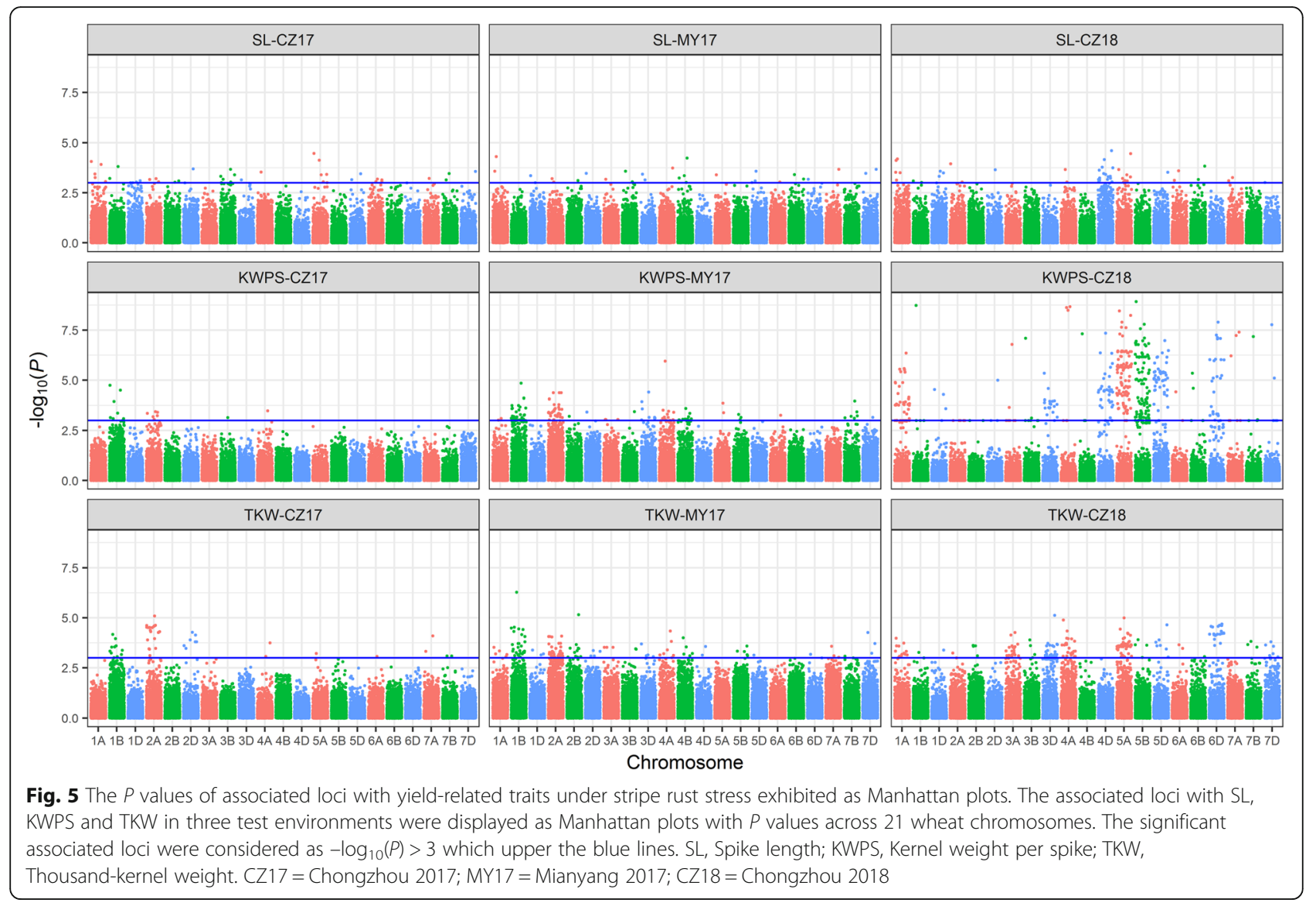

[44]. The decrease of sugar supply to the spike results in the fewer grains and smaller grains, and thus exhibited the lower KPS, KWPS and TKW.

Spikes are mainly produced from the 4-leaf stage to the heading stage, and thus SIPS is mainly determined around the 5-leaf stage to 6/7-leaf stage [28]. SlC was calculated by dividing SL by SIPS. In our study, both SL and SIPS might just escape from the major damage period of stripe rust, and thus, did not show significant differences.

The yield is the complex and comprehensive trait, which was affected by many factors. The degree of Pst infection, the time of the Pst infection, the weather, the water, the soil fertility, even the personal error for measurement, many parameters like above may affect our study. But most of all, we can be sure the infection of stripe rust can result in the decrease of KPS, KWPS and TWK in this study, which were the important components to results in the yield loss.

\section{Landraces as elite germplasm for breeding}

The 244 accessions used in this study, including 79 landraces and 165 cultivars, belong to two different germplasm resources in Sichuan Province. The classification based on the Q-matrix with Bayesian model-based clustering also clearly divided the 244 accessions into two sub-populations. Except one cultivar, accessions in sub-population 1 were all landraces, whereas those in sub-population 2 were primarily cultivars. Obvious distinctions were found in both phenotypes and genotypes between landraces and cultivars. Therefore, the utilization of these landraces should broaden the genetic background in the wheat breeding programs in Sichuan Province.

The comparison analysis for the eight yield-related traits under stripe rust stress between landraces and cultivars showed the significant differences in FTN, SIPS, KPSl, KWPS, TKW and SlC (Table 2). The landraces showed higher FTN, SIPS and SIC than cultivars. Nevertheless, the cultivars had higher KPSl, KWPS and TKW than the landraces. Besides, the landraces exhibited higher diversities in FTN, SL, SIPS and SIC based on the Shannon-Weaver diversity index, while the cultivars displayed higher diversity in KPSl, KWPS and TKW. The wheat landraces may have been shaped by traditional growth practices, while the cultivars have been developed for adapting the local cropping systems. The higher adaptability to different environments, diversity and inheritability are the basic characteristics of landraces [45]. The cultivars were bred by human-mediated selection mainly aiming at achieving high-yield. As one 
of the three yield components, kernel weight (KWPS and TKW) has been the main target of breeding. The higher KWPS and TKW of the tested cultivars were the outcomes of yield breeding for cultivars. Different from the pursuit of high yield in cultivars, the wheat landraces mainly selected by local farmers, they reserved seeds for planting, the plants with more seeds were their targets, and thus exhibiting higher FTN, SIPS and SIC and higher diversities for these traits. The traits with higher diversities are easy to modify in breeding. Many studies have demonstrated that landraces are excellent germplasm sources, especially for abiotic and biotic stresses [46-50]. Landraces also have many elite yield-related genes [51-54]. Many Chinese wheat cultivars have been developed using landraces, such as Bima 1, Shannong 205, Wuyimai, and Yulin $3[55,56]$. The represent study provides additional evidence for taking the advantages of landraces with favourable alleles for yield-related traits under stripe rust stress.

\section{Markers associated to yield-related traits}

Here, we identified 13 QTLs associated with SL, KWPS and TKW, which were located on $1 \mathrm{AL}, 1 \mathrm{BL}, 2 \mathrm{AS}, 2 \mathrm{AL}$, 2DS, 4AS, 4AL and 5AL. The QTLs associated with SL, KWPS and TKW was named as QSL.sicau, QKWPS.sicau and QTKW.sicau, respectively (Table 4). Compared the physical locations of QTLs in this study with reported QTLs or genes based on the Chinese Spring reference RefSeq v1.0 [26], three potential novel QTLs were identified. They were QSL.sicau-1AL, QTKW.sicau$4 A L$ and QKWPS.sicau-4AL.1, which were located at different physical positions from previously reported genes related to SL, TKW and KWPS.

The six QTLs were identified associated with SL, including one potentially new (QSL.sicau-1AL) and five previously reported QTLs. QSL.sicau- $2 A L$ was located around the position of $432.58 \mathrm{Mb}$ at $2 \mathrm{~A}$, which was the same as QSl.sdau-2A [57]. QSL.sicau-2DS overlapped with QPht/SL.cau-2D.2 [58], and the QSL.sicau-4AS was covered by QSl.sau-4A [59]. Two QTLs were located at 5AL. One was QSL.sicau-5AL.1, which was the same as QSL.caas-5AL that was flanked by marker $J D_{-} c 15758$ 288 and BS00041911_51 [32], and another was QSL.sicau-5AL.2, which overlapped with QSl-5A1 that was flanked by SSR marker Xbarc261 and Xbarc151 [60].

Three QTLs were associated with TKW and two with KWPS. QTKW.sicau-4AL and QKWPS.sicau-4AL.1 were potentially new based on their physical locations. QTKW.sicau-1BL.2 was located in the distal region of 1BL was covered by QTgw.ipk-1B-FS4 [61]. QTKW.sicau-2AS.1 was mapped on the short end of 2AS, which was overlapped with QTkw-2A.2 [9] and Qtkw2A-2 [62]. QKWPS.sicau-4AL.2 associated with KWPS was a major
QTL, with up to 20\% PVE. This QTL was covered by QKwps $\mid T k w-W J-4 A .1$ [63].

We also consistently detected two QTLs associated with both TKW and KWPS. QTKW.sicau-1BL.1 and QKWPS.sicau-1BL were located in the same region around $670 \mathrm{Mb}$. They were overlapped with Qgwe.ipk-1B that was associated with KWPS [64]. However, there are no reports on the association of this QTL with TKW. Our results indicated that this QTL is also related to TKW. In addition, QTKW.sicau-2AS.2 and QKWPS.sicau-2AS were also mapped at the same position of $24.05 \mathrm{Mb}$, which was very close to $Q t k w 2 A-1$ [62]. Qtkw2A-1 associated with TKW but not KWPS [62]. We found that this QTL is related to both KWPS and TKW.

We identified Qyrsicau-1BL.1 around the position of $670 \mathrm{Mb}$ that was associated with stripe rust IT and DS [27], which belonged to the same QTL block of both QTKW.sicau-1BL.1 and QKWPS.sicau-1BL. These results indicate that this QTL block around the position of $670 \mathrm{Mb}$ on $1 \mathrm{BL}$ confers stripe rust resistance, and thus related to KWPS and TKW under stripe rust stress in the present study. In addition, Qyrsicau-1BL.2 around the region of $681 \mathrm{Mb}$ associated with stripe rust IT [27] was the same as QTKW.sicau-1BL.2 which was also associated with TKW in this study. This is another QTL block conferring stripe rust resistance and thus associated to TKW. These two QTLs might be with pleiotropy were both located on $1 \mathrm{BL}$ and just $11 \mathrm{Mb}$ apart. Thus, 1BL harbours numerous QTLs for stripe rust resistance and other traits.

\section{Candidate genes for the three potentially novel QTLs}

A total of 121 genes were selected for the analyses of candidate genes of the three potential novel QTLs. Of these genes, 11,3 and 7 candidate genes were identified for QSL.sicau-1AL, QTKW.sicau-4AL and QKWPS.sicau4AL.1, respectively (Additional file 6). Eleven presumptive candidate genes (TraesCS1A02G439500, TraesCS1A02 G440000, TraesCS1A02G442400, TraesCS1A02G443700, TraesCS1A02G444100, TraesCS1A02G444500, TraesCS1A02G444700, TraesCS1A02G445100, TraesCS1A02G445200, TraesCS1A02G445300 and TraesCS1A02G445400) were speculated to exist in QSLsicau-1AL. TraesCS1A02G439500 is homologous to Arabidopsis gene $E A F 1 B$ (early flowering $1 \mathrm{~B}$ ) which involved in the regulation of transition from vegetative to reproductive phase [65] and the regulation of photoperiodism [66]. The period from vegetative to reproductive growth is important time for spike development in wheat, and the spike development is sensitive to light [28, 67-69]. TraesCS1A02G440000 is aligned with rice gene GH3.8 (Probable indole-3-acetic acid-amido synthetase), that is the auxin-responsive gene [70]. Auxin is an important hormone in plant development and we considered the homologous gene in wheat of auxin-responsive 
gene GH3.8 associates with spike development and affects the SL. TraesCS1A02G442400 is an uncharacterized protein in wheat and orthologous with Arabidopsis gene BTAF1 (TATA-binding protein-associated factor 1) involved in the positive regulation of shoot apical meristem development [71]. The shoot apical meristem is responsible for the initiation of many organs, such as nodes, leaves, spike, and inflorescence [72]. Here, we speculate that shoot apical meristems also play an important role in spike development. TraesCS1A02G443700 is the U6 snRNA-associated Sm-like protein LSM8, its orthologous gene is LSM8 in Arabidopsis, which plays a critical role in the regulation of development-related gene expression [73]. The LSM8 in wheat may also regulate the expression of spike development-related gene. TraesCS1A02G444500 is homologous to gene BAM2 (derived from barely any meristem 1) in Arabidopsis, which involved in the cell division and differentiation, floral organ development, gametophyte development and regulation of meristem growth $[74,75]$. The cell division and differentiation and meristem growth are all associated with the plant development. Hord et al. [76] reported the BAM1/BAM2 receptor-like kinases regulate the early anther development through cell division and differentiation. The spike development along with the anther development, maybe also regulated by the $B A M 2$ in wheat. TraesCS1A02G444700 is orthologous with the aspartic proteinase NANA in Arabidopsis. It's involved in the carbohydrate metabolic process, maintenance of shoot apical meristem identity and general morphology and development [77, 78]. The carbohydrate metabolic can provide the energy for spike development. The shoot apical meristem and general morphology and development all maybe involved in the spike development [79]. TraesCS1A02G444100, TraesCS1A02G445100, TraesCS1A02G445200, TraesCS1A02G445300, and TraesCS1A02G445400 were all aligned with rice gene $R R 42$ (Two-component response regulator 42), which is involved in the cytokinin-activated signaling pathway and phosphorelay signal transduction system [80, 81]. Cytokinin is the classic plant growth phytohormones and functions to promote the cell division and cell differentiation, which may contribute to the spike development in wheat.

There were three putative candidate genes for QTKW.sicau-4AL, TraesCS4A02G229100, TraesCS4A02 G229600, and TraesCS4A02G229700. TraesCS4A02G2 29100 is the auxin regulated gene involved in organ size (TaARGOS-A). Zhao et al. [82] studied the TaARGOS influenced plant growth and stress tolerance, and the GO annotation showed it involved in the positive regulation of organ growth. Its homologous gene ARGOS in rice responds to auxin stimuli, positively regulate cell and organ growth [83]. Auxin is an important hormone in plant development. In Arabidopsis, ARF2 functions as an auxin response factor playing a vital role in determining final size of the seed [84]. In rice, auxin transporters can affect kernel size and increase the TKW [85]. We speculate that TraesCS4A02G229100 as an ARGOS gene also respond to auxin and regulated the organ (spike or grain) growth in wheat. TraesCS4A02G229600 and TraesCS4A02G229700 were all orthologous with Arabidopsis gene At2g43860, as a polygalacturonase, involved in the carbohydrate metabolic process [86]. Carbohydrate is a main product of photosynthesis, and it can be transported to spikes for kernel growth and further determining kernel size and weight [10, 87].

Seven putative candidate genes, TraesCS4A02G255800, TraesCS4A02G256500, TraesCS4A02G256700, TraesCS4A02G257100, TraesCS4A02G257200, TraesCS4A02G 257700, and TraesCS4A02G258000, were detected in QKWPS.sicau-4AL.1. TraesCS4A02G255800 is homologous to the transcription factor bHLH74 (basic helixloop-helix 74) in Arabidopsis. It involved in cell elongation, plant development and triggering flowering in response to blue light [88-90]. In rice, the homologous gene bHLH74 can regulate the cell elongation and finally control the grain size [91]. Grain size, as an important yield component, may also be regulated by $b H L H 74$ homologous gene in wheat. TraesCS4A02G256500 is aligned with rice gene ACC1 (1-aminocyclopropane-1-carboxylate synthase 1 ). The $A C C 1$ is a kind of synthase, which could catalyze the formation of 1-aminocyclopropane-1-carboxylate that's a direct precursor of ethylene in higher plants. Ethylene is well known as the effect on fruit ripening and organ abscission. Yang et al. [92] found the abscisic acid and ethylene in wheat grains can respond to the drought during the grain filling. Naik and Mohapatra (2000) [93] reported the ethylene had effect on the grain filling of basal rice kernels. The grain filling is the important stage to determine the kernel yield in wheat. We speculated the homologous gene $A C C 1$ in wheat can regulate the ethylene as well and further impact the kernel yield. TraesCS4A02G256700 is the gene Wknoxla, which mainly expresses in shoot apical meristem-containing shoots and young spikes in wheat [94]. Wknoxla is aligned with rice gene OSH1, which affects the inflorescence morphology [95]. In addition, $\mathrm{OSH} 1$ regulates the auxin mediated signalling pathway [96], and as a member of the KNOX protein family, it plays an important role in shoot apical meristem maintenance [97]. Auxin and shoot apical meristems are all involved in the inflorescence development and further affect kernel traits [72, 84]. TraesCS4A02G257100 was the homolog of GDP-mannose transporter GONST1 in Arabidopsis. One of the important functions of GONST1 is carbohydrate transport [98]. It is involved in transporting carbohydrates from leaves to spikes, a vital 
activity to support kernel growth. The condition of the kernel growth would affect KWPS in wheat. TraesCS4A02G257200 is orthologous with Arabidopsis gene AMSH3. AMSH3 is essential for plant growth and development [99]. KWPS is determined by many aspects of growth and development, such as spike development, spikelet and kernel development. TraesCS4A02G257700 is the inositol-tetrakisphosphate 1-kinase and the GO annotation showed it's involved in inositol trisphosphate metabolic process. Its orthologous gene ITPK1 in maize, also involved in inositol trisphosphate metabolic process, participates in phytic acid biosynthesis in developing seeds. Phytic acid is an important storage form of phosphorus in cereal grains [100], which may influence the kernel yield directly. TraesCS4A02G258000 is homologous to COMPASS-like H3K4 histone methylase component WDR5a (WD40-REPEAT 5a) in Arabidopsis. It involved in vegetative to reproductive phase transition of meristem, and expressed in developing embryos and endosperms, shoot and root apical regions [101, 102]. The differentiation of meristem from vegetative to reproductive growth is important time for the initial of spikelet development in wheat and further impacts the yield components $[28,67]$.

Although the putative candidate genes were analysed based on collinearity analysis with the limited known information about the gene/protein function, it still provides us much important information to identify the possible candidate genes. We will further study these candidate genes by genetic mapping or reverse genetics in the future.

\section{Conclusions}

Molecular marker-assisted breeding is an effective and environment-friendly way to improve yield and disease resistance. In this study, we collected 244 accessions with high diversity from Sichuan, the phenotypic comparison analysis between resistance and susceptible accessions with or without Pst inoculation showed that the resistance accessions had much reduced yield losses (KPS, KWPS and TKW). Combined with 44,059 effective markers, we identified three potential novel loci and 16 favourable alleles through GWAS analysis, providing reliable markers and elite genetic stocks for molecular marker-assisted breeding.

\section{Materials and methods Plant materials}

A total of 244 wheat accessions (Additional file 2) were used in this study, including 79 landraces and 165 cultivars which have been used or developed by different breeding programs in Sichuan Province since 1997.

\section{Evaluation of yield-related traits and stripe rust infection type}

The 244 wheat accessions were evaluated in two locations in Sichuan with different years but all under stripe rust stress: Chongzhou (30³3'37.3" N, 103³8'45.4' E, elevation $513 \mathrm{~m}$ ) in 2017 (CZ17) and 2018 (CZ18); Mianyang $\left(31^{\circ} 23^{\prime} \mathrm{N}, 104^{\circ} 49^{\prime} \mathrm{E}\right.$, elevation $\left.440 \mathrm{~m}\right)$ in 2017 (MY17). All experimental fields were inoculated with mixed urediniospores of the local Pst races, including CYR32, CYR33, CYR34, G22-14, Su11-4, Su11-5, Su11-7 [27]. The 244 wheat accessions were also planted in different fields in Chongzhou $\left(30^{\circ} 33^{\prime} 46.3^{\prime \prime} \mathrm{N}\right.$, $103^{\circ} 38^{\prime} 38.5^{\prime \prime} \mathrm{E}$, elevation $514 \mathrm{~m}$ ) without inoculation in 2017 (CZ17ck) and 2018 (CZ18ck). This field is about $0.5 \mathrm{~km}$ away from the inoculated field and sprayed with fungicide $25 \%$ Triadimefon at the rate of $0.2 \mathrm{~kg} / \mathrm{ha}$ at the early infection stage (around booting stage for twice) and heading stage. In all test environments, twenty seeds of each accession were evenly planted in a $2 \mathrm{~m}$ row with a $0.3 \mathrm{~m}$ between rows. The accessions with three replications planted in each location were evaluated for eight yield-related traits: FTN, SL, SIPS, KPSI, KPS, KWPS, TKW, and SlC which was calculated by dividing SL by SIPS. All of the traits were measured on five randomly selected plants for each accession at harvest. The rule of identification of infection type (IT) for stripe rust was the same as Ye et al. [27]. In order to reduce the environmental impacts on yield-related traits, the best linear unbiased prediction (BLUP) values were calculated based on linear model using the lme 4 package in the $\mathrm{R}$ program [103]. The broad-sense heritability $\left(H^{2}\right)$ estimates for each of the yield-related traits were calculated across all test environments using formula $H^{2}=\mathrm{V}_{\mathrm{G}} /\left(\mathrm{V}_{\mathrm{G}}+\mathrm{V}_{\mathrm{E}}\right)$ using the lme4 package [103], where $V_{G}$ and $V_{E}$ are the genotypic and environmental variances, respectively [104]. The phenotypic variation was determined by the range, mean, standard deviation (STDEV) and coefficient of variation $(\mathrm{CV})$ for each trait and BLUP value. The Pearson correlation coefficient and the $t$-test were achieved using SPSS 20.0 (IBM Corp., Armonk, NY, USA). The Shannon-Weaver diversity index $\left(H^{\prime}\right)$ was calculated for each trait using the BLUP values [105].

\section{Genotyping analysis}

The genomic DNA was extracted from the mixed leaves collected from 5 one-week-old seedings using the plant DNA kits (Biofit Co., China) for each accession. A total of 244 DNA samples were genotyped using the $55 \mathrm{~K}$ SNP array (Affymetrix Axiom Wheat55K) at the China Golden Marker Biotechnology Company Ltd. (Beijing, China). The effective markers used for further analyses were selected with missing values $\leq 10 \%$ and minor allele frequency $(\mathrm{MAF}) \geq 5 \%$. 
Population structure, kinship and linkage disequilibrium analysis

The population structure (Q-matrix) was analysed using software STRUCTURE v2.3.4 with Bayesian modelbased clustering [106]. Five independent STRUCTURE runs were performed with the $\mathrm{K}$ from 2 to 10 using the admixture model with 100,000 replicates for burn-in length and 100,000 replicates for Markov chain Monte Carlo (MCMC) iterations. The optimal $K$ value was chosen using the $\triangle \mathrm{K}$ method in web-based software STRUCTURE HARVESTER [107]. The kinship (Kmatrix) was estimated between pairs of accessions as a measure of relatedness based on the identity-by-state (IBS) method using TASSEL v5.2.38 [108]. The pairwise measure of linkage disequilibrium (LD) was estimated as squared allele frequency correlation $\left(r^{2}\right)$ between pairs of intra-chromosomal markers with known chromosomal position using TASSEL v5.2.38 [108]. Significant pairwise markers were chosen using the threshold pDiseq $<0.001$ and $r^{2}>0.1$ [108]. The LD decay plot and half decay distance were generated with the $r^{2}$ values and the distances between markers using the ggplot2 package in the R program [109]. All high confidence associated loci in the half decay distance region on the same chromosome were defined as the same QTL block.

\section{Genome-wide association analyses}

Combining the yield-related traits under stripe rust stress with 44,059 effective SNP markers, GWAS analyses were performed on the 244 accessions using software TASSEL v5.2.38 based on the mixed linear model (MLM) with Q and $\mathrm{K}$ as covariates [108, 110, 111]. For GWAS results, a threshold $P$-value of $0.001\left(-\log _{10} P=3\right)$ was considered as the significant association markers. To make significant associated loci more reliable, the high confidence associated loci were selected for further analyses. The high confidence associated loci should be the significant association loci which must be detected in at least two test environments. The associated loci with related traits were visualized with Manhattan plots with $P$ values using the ggplot2 package in the R program [109].

\section{Analyses of high confidence significant associated loci}

There are many QTLs associated with yield-related traits previously reported. In order to identify potentially novel loci, the physical location of each QTL was determined based on the high-quality Chinese Spring reference IWGSC RefSeq v1.0 [26] using software BLAST+ v2.7.1 [112].

\section{Analyses of putative candidate genes in three potentially novel QTLs}

By referencing the Chinese Spring reference genome (IWGSC RefSeq v1.0) and RefSeq Annotation v1.1
[26], the genes included in three potentially novel QTLs were selected based on the LD decay distance $2.12 \mathrm{Mb}$. The collinear analysis was carried out using online BLAST at the EnsemblPlants website (https://plants. ensembl.org/Multi/Tools/Blast) with default parameters.

\section{Additional files}

Additional file 1: Pearson coefficient analysis for eight yield-related traits among multiple environments (XLSX $11 \mathrm{~kb}$ )

Additional file 2: Two hundred and forty-four wheat accessions used in this study and the evaluation of their yield-related traits and infection type (IT) in multiple environments (XLSX $106 \mathrm{~kb}$ )

Additional file 3: The 44,059 effective $55 \mathrm{~K}$ SNP markers used in this study (ZIP $2718 \mathrm{~kb}$ )

Additional file 4: Phenotypic variations for two sub-populations based on Q-matrix (XLSX $10 \mathrm{~kb}$ )

Additional file 5: The distribution of the favourable alleles in 244 wheat accessions (XLSX $25 \mathrm{~kb}$ )

Additional file 6: The candidate genes of three potential novel QTL (XLSX $12 \mathrm{~kb}$ )

Additional file 7: Temperatures during the wheat growth seasons in three environments. The plant growth season was from October to the following May. The lowest temperature in CZ18 was lowest among all three environments and lower than $0^{\circ} \mathrm{C}$ from December to following February. CZ17 = Chongzhou 2017; MY17= Mianyang 2017; CZ18= Chongzhou 2018 (PDF 74 kb)

\section{Abbreviations}

BLUP: Best linear unbiased prediction; CV: Coefficient of variation; CZ: Chongzhou; FTN: Fertile tiller number; GWAS: Genome-wide association study; $H^{\prime}$ : Shannon-Weaver diversity index; $H^{2}$ : Broad-sense heritability; IT: Infection type; KPS: Kernel number per spike; KPSI: Kernel number per spikelet; KWPS: Kernel weight per spike; LD: Linkage disequilibrium; MY: Mianyang; Pst: Puccinia striiformis f. sp. Tritici; QTL: Quantitative trait locus; SL: Spike length; SIC: Spikelet compactness; SIPS: Spikelet number per spike; STDEV: Standard deviation; TKW: Thousand-kernel weight

\section{Acknowledgments}

We thank Prof. Qiu-Zheng Jia (Plant Protection Research Institute, Gansu Academy of Agricultural Sciences, Lanzhou, P. R. China) for providing the Pst isolates and Prof. Li-Hui Li and Xiu-Quan Li (Chinese Academy of Agricultural Sciences) for supplying wheat germplasm (Sichuan wheat landraces).

\section{Authors' contributions}

$X Y$ carried out the experiments, analysed the data, and drafted the manuscript; JL1 carried out the phenotypic evaluation and extracted the DNA; YC carried out the analyses of association mapping; FY, LL, YW1, YW2 and $J$ L2 carried out the phenotypic evaluation; JW provided the genotype data; HK, CL YL, YJ and XC contributed to revising the manuscript; $Q J, P Q$, $\mathrm{WL}, \mathrm{XL}, J \mathrm{M}$ and $\mathrm{YW} 3$ participated in the field experiments; $Y Z$ participated in the design of the experiments; GC formulated the questions, designed and carried out the experiments, analysed the data and revised the manuscript. All authors have reviewed and approved the final manuscript.

\section{Funding}

This publication is based upon work supported by the projects from the National Key Research and Development Program of China (2016YFD0102000, 2016YFD0100100, 2017YFD0100900), and the International Science and Technology Cooperation and Exchanges Programs of Science and Technology Department of Sichuan Province (2019YFH0063). The funders had no role in the study design, collection, analysis and interpretation of data, or in the writing of the report or decision to submit the article for publication. 


\section{Availability of data and materials}

Not applicable.

\section{Ethics approval and consent to participate}

Not applicable.

\section{Consent for publication}

Not applicable.

\section{Competing interests}

The authors declare that they have no competing interests.

\section{Author details}

${ }^{1}$ Triticeae Research Institute, Sichuan Agricultural University, Wenjiang, Chengdu, Sichuan 611130, People's Republic of China. ${ }^{2}$ College of Agronomy, Sichuan Agricultural University, Wenjiang, Chengdu, Sichuan 611130, People's Republic of China. ${ }^{3}$ US Department of Agriculture, Agricultural Research Service, Wheat Health, Genetics and Quality Research Unit; and Department of Plant Pathology, Washington State University, Pullman, WA 99164-6430, USA. ${ }^{4}$ CSIRO Agriculture and Food, St Lucia, Queensland 4067, Australia.

Received: 27 May 2019 Accepted: 29 July 2019

Published online: 08 August 2019

\section{References}

1. Brenchley R, Spannagl M, Pfeifer M, Barker GL, D'Amore R, Allen AM, McKenzie N, Kramer M, Kerhornou A, Bolser D, et al. Analysis of the bread wheat genome using whole-genome shotgun sequencing. Nature. 2012; 491(7426):705-10.

2. Khanfri S, Boulif M, Lahlali R. Yellow rust (Puccinia striiformis): a serious threat to wheat production worldwide. Not Sci Biol. 2018;10(3):410-23.

3. Ma Z, Zhao D, Zhang C, Zhang Z, Xue S, Lin F, Kong Z, Tian D, Luo Q. Molecular genetic analysis of five spike-related traits in wheat using RIL and immortalized $F_{2}$ populations. Mol Gen Genomics. 2007;277(1):31-42.

4. Guo Z, Chen D, Alqudah AM, Röder MS, Ganal MW, Schnurbusch T. Genomewide association analyses of 54 traits identified multiple loci for the determination of floret fertility in wheat. New Phytol. 2017;214(1):257-70.

5. Liu J, Xu Z, Fan X, Zhou Q, Cao J, Wang F, Ji G, Yang L, Feng B, Wang T. A genome-wide association study of wheat spike related traits in China. Front Plant Sci. 2018;9:1584.

6. Zhai H, Feng Z, Li J, Liu X, Xiao S, Ni Z, Sun Q. QTL analysis of spike morphological traits and plant height in winter wheat (Triticum aestivum L.) using a high-density SNP and SSR-based linkage map. Front Plant Sci. 2016;7:1617.

7. Würschum T, Leiser WL, Langer SM, Tucker MR, Longin CFH. Phenotypic and genetic analysis of spike and kernel characteristics in wheat reveals longterm genetic trends of grain yield components. Theor Appl Genet. 2018; 131(10):2071-84

8. Mohsin T, Khan N, Naqvi FN. Heritability, phenotypic correlation and path coefficient studies for some agronomic characters in synthetic elite lines of wheat. J Food Agric Environ. 2009;7(3-4):278-82.

9. Cui F, Zhao C, Ding A, Li J, Wang L, Li X, Bao Y, Li J, Wang H. Construction of an integrative linkage map and QTL mapping of grain yield-related traits using three related wheat RIL populations. Theor Appl Genet. 2014;127(3):659-75.

10. Meyer U, Köllner B, Willenbrink J, Krause GHM. Effects of different ozone exposure regimes on photosynthesis, assimilates and thousand grain weight in spring wheat. Agric Ecosyst Environ. 2000;78(1):49-55.

11. Foulkes MJ, Slafer GA, Davies WJ, Berry PM, Sylvester-Bradley R, Martre P, Calderini DF, Griffiths S, Reynolds MP. Raising yield potential of wheat. III. Optimizing partitioning to grain while maintaining lodging resistance. J Exp Bot. 2010;62(2):469-86.

12. Altshuler D, Daly MJ, Lander ES. Genetic mapping in human disease. Science. 2008;322(5903):881-8.

13. Manolio TA, Collins FS, Cox NJ, Goldstein DB, Hindorff LA, Hunter DJ, McCarthy MI, Ramos EM, Cardon LR, Chakravarti A, et al. Finding the missing heritability of complex diseases. Nature. 2009;461(7265):747-53.

14. Samocha KE, Robinson EB, Sanders SJ, Stevens C, Sabo A, McGrath LM, Kosmicki JA, Rehnström K, Mallick S, Kirby A, et al. A framework for the interpretation of de novo mutation in human disease. Nat Genet. 2014; 46(9):944-50.

15. Greene CS, Krishnan A, Wong AK, Ricciotti E, Zelaya RA, Himmelstein DS, Zhang R, Hartmann BM, Zaslavsky E, Sealfon SC, et al. Understanding multicellular function and disease with human tissue-specific networks. Nat Genet. 2015;47(6):569-76.

16. Emilsson V, Ilkov M, Lamb JR, Finkel N, Gudmundsson EF, Pitts R, Hoover H, Gudmundsdottir V, Horman SR, Aspelund T, et al. Co-regulatory networks of human serum proteins link genetics to disease. Science. 2018;361(6404):769-73.

17. Huang X, Sang T, Zhao Q, Feng Q, Zhao Y, Li C, Zhu C, Lu T, Zhang Z, Li M, et al. Genome-wide association studies of 14 agronomic traits in rice landraces. Nat Genet. 2010:42(11):961-7.

18. Johnston SE, MCEWAN JC, Pickering NK, Kijas JW, Beraldi D, Pilkington JG, Pemberton JM, Slate JON. Genome-wide association mapping identifies the genetic basis of discrete and quantitative variation in sexual weaponry in a wild sheep population. Mol Ecol. 2011:20(12):2555-66.

19. Diniz DB, Lopes MS, Broekhuijse ML, Lopes PS, Harlizius B, Guimarães SEF, Duijvesteijn N, Knol EF, Silva FF. A genome-wide association study reveals a novel candidate gene for sperm motility in pigs. Anim Reprod Sci. 2014; 151(3-4):201-7.

20. Sukumaran S, Dreisigacker S, Lopes M, Chavez P, Reynolds MP. Genomewide association study for grain yield and related traits in an elite spring wheat population grown in temperate irrigated environments. Theor Appl Genet. 2015;128(2):353-63.

21. Rashid Z, Singh PK, Vemuri H, Zaidi PH, Prasanna BM, Nair SK. Genome-wide association study in Asia-adapted tropical maize reveals novel and explored genomic regions for sorghum downy mildew resistance. Sci Rep. 2018;8(1):366

22. Zegeye H, Rasheed A, Makdis F, Badebo A, Ogbonnaya FC. Genome-wide association mapping for seedling and adult plant resistance to stripe rust in synthetic hexaploid wheat. PLoS One. 2014;9(8):e105593.

23. Chen G, Zhang H, Deng Z, Wu R, Li D, Wang M, Tian J. Genome-wide association study for kernel weight-related traits using SNPs in a Chinese winter wheat population. Euphytica. 2016;212(2):173-85.

24. Liu N, Bai G, Lin M, Xu X, Zheng W. Genome-wide association analysis of powdery mildew resistance in US winter wheat. Sci Rep. 2017:7(1):11743.

25. Godoy J, Gizaw S, Chao S, Blake N, Carter A, Cuthbert R, Dubcovsky J, Hucl P, Kephart K, Pozniak C, et al. Genome-wide association study of agronomic traits in a spring-planted north American elite hard red spring wheat panel. Crop Sci. 2018;58(5):1838-52.

26. Appels R, Eversole K, Feuillet C, Keller B, Rogers J, Stein N, Pozniak CJ, Choulet F, Distelfeld A, Poland J, et al. Shifting the limits in wheat research and breeding using a fully annotated reference genome. Science. 2018;361(6403):eaar7191.

27. Ye X, Li J, Cheng Y, Yao F, Long L, Yu C, Wang Y, Wu Y, Li J, Wang J, et al. Genome-wide association study of resistance to stripe rust (Puccinia striiformis f. sp. tritici) in Sichuan wheat. BMC Plant Biol. 2019;19(1):147.

28. White J, Edwards J. Wheat growth and development. Department of Primary Industries: Orange; 2008.

29. Rüegger A, Winzeler H, Nösberger J. Dry matter production and distribution of $14 \mathrm{C}$ - assimilates of spelt (Triticum spelta L.) and wheat (Triticum aestivum L.) as influenced by different temperatures before and during grain filling. J Agron Crop Sci. 1990;165(2-3):110-20.

30. Bos HJ. Neuteboom J.H. morphological analysis of leaf and tiller number dynamics of wheat (Triticum aestivum L.): responses to temperature and light intensity. Ann Bot. 1998;81(1):131-9.

31. Kashif M, Khaliq I. Heritability, correlation and path coefficient analysis for some metric traits in wheat. Int J Agric Biol. 2004;6(1):138-42.

32. Gao F, Wen W, Liu J, Rasheed A, Yin G, Xia X, Wu X, He Z. Genome-wide linkage mapping of QTL for yield components, plant height and yieldrelated physiological traits in the Chinese wheat cross Zhou 8425B/Chinese spring. Front Plant Sci. 2015;6:1099.

33. Zhou Y, Conway B, Miller D, Marshall D, Cooper A, Murphy P, Chao S, Brown-Guedira G, Costa J. Quantitative trait loci mapping for spike characteristics in hexaploid wheat. Plant Genome. 2017:10(2):1-15.

34. Wang R, Liu Y, Isham K, Zhao W, Wheeler J, Klassen N, Hu Y, Bonman JM, Chen J. QTL identification and KASP marker development for productive tiller and fertile spikelet numbers in two high-yielding hard white spring wheat cultivars. Mol Breed. 2018;38(11):135.

35. Li HQ, Zhang HG, Liu BL, Liu DC, Zhang B. Assessing genetic diversity and its changes of bread wheat in Qinghai Province, China, using agronomic traits and microsatellite markers. Biol Agric Horticul. 2012;28(2):120-8. 
36. Liu Y, Lin Y, Gao S, Li Z, Ma J, Deng M, Chen G, Wei Y, Zheng Y. A genomewide association study of 23 agronomic traits in Chinese wheat landraces. Plant J. 2017;91(5):861-73.

37. Conner RL, Kuzyk AD. Effectiveness of fungicides in controlling stripe rust, leaf rust, and black point in soft white spring wheat. Can J Plant Pathol. 1988;10(4):321-6.

38. Murray GM, Ellison PJ, Watson A. Effects of stripe rust on the wheat plant. Australas Plant Pathol. 1995;24(4):261-70.

39. Smith RCG, Heritage AD, Stapper M, Barrs HD. Effect of stripe rust (Puccinia striiformis west.) and irrigation on the yield and foliage temperature of wheat. Field Crops Res. 1986;14:39-51.

40. Schultz TR, Line RF. High-temperature, adult-plant resistance to wheat stripe rust and effects on yield components. Agron J. 1992;84(2):170-5.

41. Sharma RC, Nazari K, Amanov A, Ziyaev Z, Jalilov AU. Reduction of winter wheat yield losses caused by stripe rust through fungicide management. J Phytopathol. 2016;164(9):671-7.

42. Herrera-Foessel SA, Singh RP, Huerta-Espino J, Crossa J, Yuen J, Djurle A. Effect of leaf rust on grain yield and yield traits of durum wheats with race-specific and slow-rusting resistance to leaf rust. Plant Dis. 2006;90(8):1065-72.

43. Fischer RA. Selection traits for improving yield potential. Application of physiology in wheat breeding. Mexico: CIMMYT; 2001. p. 148-59.

44. Murray DG, Murray GM. Stripe rust: understanding the disease in wheat. NSW: Department of Primary Industries; 2005.

45. Jaradat AA. Wheat landraces: genetic resources for sustenance and sustainability. usda-ars; 2011. p. 1-20.

46. Huang XQ, Hsam SLK, Zeller FJ, Wenzel G, Mohler V. Molecular mapping of the wheat powdery mildew resistance gene Pm24 and marker validation for molecular breeding. Theor Appl Genet. 2000;101(3):407-14.

47. Reynolds M, Dreccer F, Trethowan R. Drought-adaptive traits derived from wheat wild relatives and landraces. J Exp Bot. 2006;58(2):177-86.

48. Xiao M, Song F, Jiao J, Wang X, Xu H, Li H. Identification of the gene Pm47 on chromosome 7BS conferring resistance to powdery mildew in the Chinese wheat landrace Hongyanglazi. Theor Appl Genet. 2013; 126(5):1397-403.

49. Wang M, Chen X. Stripe Rust: Stripe Rust Resistance. Dordrecht: Springer; 2017.

50. Tan C, Li G, Cowger C, Carver BF, Xu X. Characterization of Pm59, a novel powdery mildew resistance gene in Afghanistan wheat landrace PI 181356. Theor Appl Genet. 2018;131(5):1145-52.

51. Su Z, Hao C, Wang L, Dong Y, Zhang X. Identification and development of a functional marker of TaGW2 associated with grain weight in bread wheat (Triticum aestivum L.). Theor Appl Genet. 2011;122(1):211-23.

52. Zhang L, Zhao YL, Gao LF, Zhao GY, Zhou RH, Zhang BS, Jia JZ. TaCKX6-D1, the ortholog of rice OsCKX2, is associated with grain weight in hexaploid wheat. New Phytol. 2012;195(3):574-84.

53. Wang $S$, Zhang $X$, Chen F, Cui D. A single-nucleotide polymorphism of TaGS5 gene revealed its association with kernel weight in Chinese bread wheat. Front Plant Sci. 2015;6:1166.

54. Ma L, Li T, Hao C, Wang Y, Chen X, Zhang X. TaGS5-3A, a grain size gene selected during wheat improvement for larger kernel and yield. Plant Biotechnol J. 2016;14(5):1269-80.

55. He ZH. A history of wheat breeding in China. CIMMYT: Mexico; 2001. p. 11-2.

56. He ZH, Xia XC, Bonjean AP. Wheat improvement in China. Cereals in China. Mexico: CIMMYT; 2010. p. 59-62.

57. Deng Z, Cui Y, Han Q, Fang W, Li J, Tian J. Discovery of consistent QTLs of wheat spike-related traits under nitrogen treatment at different development stages. Front Plant Sci. 2017:8:2120.

58. Chai L, Chen Z, Bian R, Zhai H, Cheng X, Peng H, Yao Y, Hu Z, Xin M, Guo $W$, et al. Dissection of two quantitative trait loci with pleiotropic effects on plant height and spike length linked in coupling phase on the short arm of chromosome 2D of common wheat (Triticum aestivum L.). Theor Appl Genet. 2018;131(12):2621-37.

59. Luo W, Ma J, Zhou XH, Sun M, Kong XC, Wei YM, Jiang YF, Qi PF, Jiang QT, Liu YX, et al. Identification of quantitative trait loci controlling yield-related traits indicates breeding potential of Tibetan semiwild wheat (Triticum aestivum ssp. tibetanum). Crop Sci. 2016;56(5):2410-20.

60. Liu G, Jia L, Lu L, Qin D, Zhang J, Guan P, Ni Z, Yao Y, Sun Q, Peng H. Mapping QTLs of yield-related traits using RIL population derived from common wheat and Tibetan semi-wild wheat. Theor Appl Genet. 2014; 127(11):2415-32.

61. Nezhad KZ, Weber WE, Röder MS, Sharma S, Lohwasser U, Meyer RC, Saal B, Börner A. QTL analysis for thousand-grain weight under terminal drought stress in bread wheat (Triticum aestivum L.). Euphytica. 2012;186(1):127-38.
62. Zhang X, Deng Z, Wang Y, Li J, Tian J. Unconditional and conditional QTL analysis of kernel weight related traits in wheat (Triticum aestivum L.) in multiple genetic backgrounds. Genetica. 2014;142(4):371-9.

63. Cui F, Zhao CH, Li J, Ding AM, Li XF, Bao YG, Li J, Ji J, Wang HG. Kernel weight per spike: what contributes to it at the individual QTL level? Mol Breed. 2013;31(2):265-78.

64. Börner A, Schumann E, Fürste A, Cöster H, Leithold B, Röder M, Weber W. Mapping of quantitative trait loci determining agronomic important characters in hexaploid wheat (Triticum aestivum L.). Theor Appl Genet. 2002;105(6-7):921-36.

65. Scott DB, Jin W, Ledford HK, Jung HS, Honma MA. EAF1 regulates vegetative-phase change and flowering time in Arabidopsis. Plant Physiol. 1999;120(3):675-84.

66. Bieluszewski T, Galganski L, Sura W, Bieluszewska A, Abram M, Ludwikow A, Ziolkowski PA, Sadowski J. AtEAF1 is a potential platform protein for Arabidopsis NuA4 acetyltransferase complex. BMC Plant Biol. 2015;15(1):7590.

67. Bonnett OT. The development of the wheat spike. J Agric Res. 1936;53(6): 445-51.

68. Friend DJ. Ear length and spikelet number of wheat grown at different temperatures and light intensities. Can J Bot. 1965;43(3):345-53.

69. Gardner JS, Hess WM, Trione EJ. Development of the young wheat spike: a SEM study of Chinese spring wheat. Am J Bot. 1985;72(4):548-59.

70. Jain M, Kaur N, Tyagi AK, Khurana JP. The auxin-responsive GH3 gene family in rice (Oryza sativa). Funct Integr Genom. 2006;6(1):36-46.

71. Tamaki H, Konishi M, Daimon Y, Aida M, Tasaka M, Sugiyama M. Identification of novel meristem factors involved in shoot regeneration through the analysis of temperature-sensitive mutants of Arabidopsis. Plant J. 2009;57(6):1027-39.

72. Babb S, Muehlbauer G. Genetic and morphological characterization of the barley uniculm2 (cul2) mutant. Theor Appl Genet. 2003;106(5):846-57.

73. Perea-Resa C, Hernández-Verdeja T, López-Cobollo R, del Mar CM, Salinas J. LSM proteins provide accurate splicing and decay of selected transcripts to ensure normal Arabidopsis development. Plant Cell. 2012;24(12):4930-47.

74. DeYoung BJ, Bickle KL, Schrage KJ, Muskett P, Patel K, Clark SE. The CLAVATA1-related BAM1, BAM2 and BAM3 receptor kinase-like proteins are required for meristem function in Arabidopsis. Plant J. 2006;45(1):1-6.

75. Sun $\mathrm{YJ}$, Hord $\mathrm{CL}$, Chen $\mathrm{CB}, \mathrm{Ma} \mathrm{H}$. Regulation of Arabidopsis early anther development by putative cell-cell signaling molecules and transcriptional regulators. J Integr Plant Biol. 2007;49(1):60-8.

76. Hord CL, Chen C, DeYoung BJ, Clark SE, Ma H. The BAM1/BAM2 receptor-like kinases are important regulators of Arabidopsis early anther development. Plant Cell. 2006;18(7):1667-80.

77. Paparelli E, Gonzali S, Parlanti S, Novi G, Giorgi FM, Licausi F, Kosmacz M, Feil R, Lunn JE, Brust H, et al. Misexpression of a chloroplast aspartyl protease leads to severe growth defects and alters carbohydrate metabolism in Arabidopsis. Plant Physiol. 2012;160(3):1237-50.

78. Albert EV, Kavai-ool UN, Ezhova TA. Gene NANA regulates cell proliferation in Arabidopsis thaliana shoot apical meristem without interaction with CLV1, CLV2, CLV3. Russ J Dev Biol. 2014;45(5):267-72.

79. Kirby EJ. Ear development in spring wheat. J Agric Sci. 1974;82(3):437-47.

80. Hwang I, Sheen J. Two-component circuitry in Arabidopsis cytokinin signal transduction. Nature. 2001:413(6854):383-9.

81. Sakai H, Honma T, Aoyama T, Sato S, Kato T, Tabata S, Oka A. ARR1, a transcription factor for genes immediately responsive to cytokinins. Science. 2001;294(5546):1519-21.

82. Zhao Y, Tian X, Li Y, Zhang L, Guan P, Kou X, Wang X, Xin M, Hu Z, Yao Y, et al. Molecular and functional characterization of wheat ARGOS genes influencing plant growth and stress tolerance. Front Plant Sci. 2017;8:170.

83. Wang $B$, Sang $Y$, Song J, Gao XQ, Zhang X. Expression of a rice OsARGOS gene in Arabidopsis promotes cell division and expansion and increases organ size. J Genet Genomics. 2009;36(1):31-40.

84. Schruff MC, Spielman M, Tiwari S, Adams S, Fenby N, Scott RJ. The AUXIN RESPONSE FACTOR 2 gene of Arabidopsis links auxin signalling, cell division, and the size of seeds and other organs. Development. 2006;133(2):251-61.

85. Liu L, Tong H, Xiao Y, Che R, Xu F, Hu B, Liang C, Chu J, Li J, Chu C. Activation of big Grain1 significantly improves grain size by regulating auxin transport in rice. Proc Natl Acad Sci. 2015;112(35):11102-7.

86. Gaudet P, Livstone MS, Lewis SE, Thomas PD. Phylogenetic-based propagation of functional annotations within the gene ontology consortium. Brief Bioinform. 2011;12(5):449-62. 
87. Ceylan Y, Kutman UB, Mengutay M, Cakmak I. Magnesium applications to growth medium and foliage affect the starch distribution, increase the grain size and improve the seed germination in wheat. Plant Soil. 2016;406(1-2): $145-56$.

88. Zhang LY, Bai MY, Wu J, Zhu JY, Wang H, Zhang Z, Wang W, Sun Y, Zhao J, Sun $X$, et al. Antagonistic HLH/bHLH transcription factors mediate brassinosteroid regulation of cell elongation and plant development in rice and Arabidopsis. Plant Cell. 2009;21(12):3767-80.

89. Ikeda M, Fujiwara S, Mitsuda N, Ohme-Takagi M. A triantagonistic basic helix-loop-helix system regulates cell elongation in Arabidopsis. Plant Cell. 2012;24(11):4483-97.

90. Liu Y, Li X, Li K, Liu H, Lin C. Multiple bHLH proteins form heterodimers to mediate CRY2-dependent regulation of flowering-time in Arabidopsis. PLoS Genet. 2013;9(10):e1003861.

91. Heang D, Sassa $H$. An atypical bHLH protein encoded by POSITIVE REGULATOR OF GRAIN LENGTH 2 is involved in controlling grain length and weight of rice through interaction with a typical bHLH protein APG. Breed Sci. 2012;62(2):133-41.

92. Yang J, Zhang J, Liu K, Wang Z, Liu L. Abscisic acid and ethylene interact in wheat grains in response to soil drying during grain filling. New Phytol. 2006:171(2):293-303

93. Naik PK, Mohapatra PK. Ethylene inhibitors enhanced sucrose synthase activity and promoted grain filling of basal rice kernels. Funct Plant Biol. 2000;27(11):997-1008.

94. Takumi S, Kosugi T, Murai K, Mori N, Nakamura C. Molecular cloning of three homoeologous cDNAs encoding orthologs of the maize KNOTTED1 homeobox protein from young spikes of hexaploid wheat. Gene. 2000; 249(1-2):171-81.

95. Tsuda K, Ito $Y$, Sato $Y$, Kurata N. Positive autoregulation of a KNOX gene is essential for shoot apical meristem maintenance in rice. Plant Cell. 2011; 23(12):4368-81.

96. Song S, Chen Y, Liu L, See YHB, Mao C, Gan Y, Yu H. OsFTIP7 determines auxin-mediated anther dehiscence in rice. Nat Plants. 2018;4(7):495-504.

97. Zhang D, Yuan Z. Molecular control of grass inflorescence development. Annu Rev Plant Biol. 2014;65:553-78.

98. Baldwin TC, Handford MG, Yuseff MI, Orellana A, Dupree P. Identification and characterization of GONST1, a Golgi-localized GDP-mannose transporter in Arabidopsis. Plant Cell. 2001:13(10):2283-95.

99. Kalinowska K, Nagel MK, Goodman K, Cuyas L, Anzenberger F, Alkofer A, Paz-Ares J, Braun P, Rubio V, Otegui MS, Isono E. Arabidopsis ALIX is required for the endosomal localization of the deubiquitinating enzyme AMSH3. Proc Natl Acad Sci. 2015;112(40):5543-51.

100. Shi J, Wang H, Wu Y, Hazebroek J, Meeley RB, Ertl DS. The maize low-phytic acid mutant lpa2 is caused by mutation in an inositol phosphate kinase gene. Plant Physiol. 2003;131(2):507-15.

101. Jiang D, Gu X, He Y. Establishment of the winter-annual growth habit via FRIGIDA-mediated histone methylation at FLOWERING LOCUS C in Arabidopsis. Plant Cell. 2009;21(6):1733-46.

102. Jiang D, Kong NC, Gu X, Li Z, He Y. Arabidopsis COMPASS-like complexes mediate histone $\mathrm{H} 3$ lysine-4 trimethylation to control floral transition and plant development. PLoS Genet. 2011;7(3):e1001330.

103. Bates D, Maechler M, Bolker B, Walker S. Ime4: linear mixed-effects models using Eigen and S4. R package version. 2014;1(7):1-23.

104. Smith SE, Kuehl RO, Ray IM, Hui R, Soleri D. Evaluation of simple methods for estimating broad-sense heritability in stands of randomly planted genotypes. Crop Sci. 1998;38:1125-9.

105. Li R, Zeng Y, Xu J, Wang Q, Wu F, Cao M, Lan H, Liu Y, Lu Y. Genetic variation for maize root architecture in response to drought stress at the seedling stage. Breed Sci. 2015;65(4):298-307.

106. Evanno G, Regnaut S, Goudet J. Detecting the number of clusters of individuals using the software STRUCTURE: a simulation study. Mol Ecol. 2005;14(8):2611-20.

107. Earl DA. STRUCTURE HARVESTER: a website and program for visualizing STRUCTURE output and implementing the Evanno method. Conservation Genet Resour. 2012;4(2):359-61.

108. Bradbury PJ, Zhang Z, Kroon DE, Casstevens TM, Ramdoss Y, Buckler ES. TASSEL: software for association mapping of complex traits in diverse samples. Bioinformatics. 2007;23(19):2633-5.

109. Wickham H. ggplot2: elegant graphics for data analysis. New York: Springer; 2016.
110. Yu J, Pressoir G, Briggs WH, Bi IV, Yamasaki M, Doebley JF, McMullen MD, Gaut BS, Nielsen DM, Holland JB, et al. A unified mixed-model method for association mapping that accounts for multiple levels of relatedness. Nat Genet. 2006;38(2):203-8.

111. Zhang Z, Ersoz E, Lai CQ, Todhunter RJ, Tiwari HK, Gore MA, Bradbury PJ, Yu J, Arnett DK, Ordovas JM, et al. Mixed linear model approach adapted for genome-wide association studies. Nat Genet. 2010;42:355-60.

112. Camacho C, Coulouris G, Avagyan V, Ma N, Papadopoulos J, Bealer K, Madden TL. BLAST+: architecture and applications. BMC Bioinformatics. 2009;10(1):421.

\section{Publisher's Note}

Springer Nature remains neutral with regard to jurisdictional claims in published maps and institutional affiliations.
Ready to submit your research? Choose BMC and benefit from:

- fast, convenient online submission

- thorough peer review by experienced researchers in your field

- rapid publication on acceptance

- support for research data, including large and complex data types

- gold Open Access which fosters wider collaboration and increased citations

- maximum visibility for your research: over $100 \mathrm{M}$ website views per year

At BMC, research is always in progress.

Learn more biomedcentral.com/submissions 